\title{
Cell size matters: Nano- and micro-plastics preferentially drive declines of large marine phytoplankton due to co-aggregation
}

\author{
Craig J. Dedman ${ }^{\mathrm{a}, *, 1}$, Joseph A. Christie-Oleza ${ }^{\mathrm{a}, \mathrm{b}, \text { ***}}$, Víctor Fernández-Juárez ${ }^{\mathrm{b}, 2}$, \\ Pedro Echeveste ${ }^{\mathrm{c}, \mathrm{d}, \cdots \cdots *}$ \\ ${ }^{a}$ School of Life Sciences, Gibbet Hill Campus, University of Warwick, Coventry CV4 7AL, United Kingdom \\ ${ }^{\mathrm{b}}$ Department of Biology, University of the Balearic Islands, Ctra. Valldemossa, km 7.5, CP: 07122, Palma, Spain \\ ${ }^{\mathrm{c}}$ Instituto de Ciencias Naturales Alexander von Humboldt, Universidad de Antofagasta, Antofagasta, Chile \\ ${ }^{\mathrm{d}}$ Instituto Milenio de Oceanografía, Concepción, Chile
}

\section{A R T I C L E I N F O}

\section{Keywords:}

Microplastics

Nanoplastics

Ecotoxicology

Phytoplankton

Cell size

\begin{abstract}
A B S T R A C T
Marine plastic pollution represents a key environmental concern. Whilst ecotoxicological data for plastic is increasingly available, its impact upon marine phytoplankton remains unclear. Owing to their predicted abundance in the marine environment and likely interactions with phytoplankton, here we focus on the smaller fraction of plastic particles ( $\sim 50 \mathrm{~nm}$ and $\sim 2 \mu \mathrm{m}$ polystyrene spheres). Exposure of natural phytoplankton communities and laboratory cultures revealed that plastic exposure does not follow traditional trends in ecotoxicological research, since large phytoplankton appear particularly susceptible towards plastics exposure despite their lower surface-to-volume ratios. Cell declines appear driven by hetero-aggregation and cosedimentation of cells with plastic particles, recorded visually and demonstrated using confocal microscopy. As a consequence, plastic exposure also caused disruption to photosynthetic functioning, as determined by both photosynthetic efficiency and high throughput proteomics. Negative effects upon phytoplankton are recorded at concentrations orders of magnitude above those estimated in the environment. Hence, it is likely that impacts of NPs and MPs are exacerbated at the high concentrations typically used in ecotoxicological research (i.e., $\mathrm{mg} \mathrm{L}^{-1}$ ).
\end{abstract}

\section{Introduction}

The occurrence of plastic debris within the global ocean appears ubiquitous and represents a major environmental concern (Cole et al., 2011; Andrady, 2011). Estimates predict that 4.8-12.7 million tons of plastic enter the marine environment every year (Jambeck et al., 2015), and currently up to 5.35 trillion plastic particles are believed to be carried along ocean currents where they may interact with marine species (Eriksen et al., 2014). Research pertaining to the environmental fate of plastic pollution and its interaction with biota has increased dramatically over the past decade (Cole et al., 2011; Andrady, 2011; Hidalgo-Ruz et al., 2012; Cozar et al., 2014). Here, investigation has primarily focussed upon the occurrence of plastic particles $<5 \mathrm{~mm}$, termed microplastics (Cole et al., 2011; Andrady, 2011; Thompson et al.,
2004). Such particles have been found to display the potential to exert adverse impacts upon marine biota spanning various trophic levels and may ultimately affect human health through the consumption of marine aquaculture products (Cole et al., 2011, 2013; Wright et al., 2013; Galloway and Lewis, 2016).

Microplastics are believed likely to continually fragment in the natural environment until completely mineralised, forming particles of an ever-decreasing size, eventually giving rise to nanoplastics $(<1 \mu \mathrm{m})$ (Andrady, 2011; Lambert and Wagner, 2016; Lambert et al., 2013; Mattsson et al., 2015; Koelmans et al., 2015). This definition is still under debate, where others define nanoplastics as those particles $<100$ $\mathrm{nm}$, in-line with the classification of metal- and metal oxide nanomaterials (Andrady, 2011; Lambert and Wagner, 2016; Lambert et al., 2013; Mattsson et al., 2015; Koelmans et al., 2015; Klaine et al., 2008;

\footnotetext{
* Corresponding author.

** Corresponding author at: Department of Biology, University of the Balearic Islands, Ctra. Valldemossa, km 7.5, CP: 07122, Palma, Spain

$* * *$ Corresponding author at: Instituto de Ciencias Naturales Alexander von Humboldt, Universidad de Antofagasta, Antofagasta, Chile.

E-mail addresses: craig.dedman@earth.ox.ac.uk (C.J. Dedman), joseph.christie@uib.eu (J.A. Christie-Oleza), pedro.echeveste@uantof.cl (P. Echeveste).

1 Department of Earth Sciences, University of Oxford, 3 S Parks Rd, Oxford OX1 3AN.

2 Marine Biological Section, Department of Biology, University of Copenhagen, Helsingør, Denmark.
} 
Hartmann et al., 2019). The fragmentation of microplastics into nanoplastics has been demonstrated under laboratory conditions (Lambert and Wagner, 2016; Enfrin et al., 2020). For example, shear forces which occur during wastewater processing is observed to cause fragmentation of microplastics released from 'facial scrubbers' found in facewash (Enfrin et al., 2020). It is believed that in the environment, one microplastic particle $\left(5 \mathrm{~mm}\right.$ ) could fragment into $10^{14}$ nanoplastics sized 100 nm (Koelmans et al., 2015; Wagner and Reemtsma, 2019; Besseling et al., 2019). As such, the quantity of nano-sized plastic debris in the environment is likely to far exceed those predicted for microplastics.

Environmental sampling highlights a missing fraction of plastic particles $<1 \mathrm{~mm}$, believed the cause of underestimations of the global oceanic load of plastic debris (Cozar et al., 2014; Poulain et al., 2019). As such, uncertainties still exist in the true environmental concentration of small plastic particles. The abundance and distribution of plastic particles sized $<250 \mu \mathrm{m}$ across the global ocean is not known (Pabortsava and Lampitt, 2020). Analytical techniques have been insufficient to accurately ascertain concentrations of these small plastic particles in the environment, which often pass through mesh during sampling (Hidalgo-Ruz et al., 2012; Wagner and Reemtsma, 2019; Pabortsava and Lampitt, 2020; Nguyen et al., 2019; Everaert et al., 2018). Hence, researchers face great difficulty in correctly assessing the plastic budget of particles below the $\mu \mathrm{m}$ range. However, recent field investigations carried out by Pabortsava and Lampitt (2020) revealed that small plastic fragments which are contained within the ocean interior can account for the "missing sink" of plastic previously described. Based on the evidence currently available the concentration of small plastics in the $\mu \mathrm{m}$ and $\mathrm{nm}$ size range appears to be in the low $\mu \mathrm{g} \mathrm{L} \mathrm{L}^{-1}$ range (Pabortsava and Lampitt, 2020; Lenz et al., 2016). Novel approaches are being developed to accurately monitor and characterise small plastic fragments, requiring multiple analytical techniques working simultaneously (Nguyen et al., 2019). Despite analytical challenges, nanoplastics have been identified in the environment (Ter Halle et al., 2017). For instance, Ter halle et al. (2017) reported the occurrence of various polymers of nanoplastics within the North Atlantic subtropical gyre. Uncertainty regarding the true volume of plastic pollution within the global ocean is likely to change as our analytical capabilities advance. Due to differing physical and chemical behaviour in the nanoscale, nanoplastics are likely to display significantly altered fate within the marine environment compared to microplastics (Wagner and Reemtsma, 2019; Hassan et al., 2015; Hotze et al., 2010). Their small size increases the surface area-volume ratio of particles, increasing reactivity and enhancing their ability to absorb other contaminants within the water column, as well as enhancing bioavailability (Mattsson et al., 2015; Wagner and Reemtsma, 2019).

The marine phototrophic community contributes approximately $50 \%$ of global primary productivity (Field et al., 1998), and contributes to major biogeochemical and climatic cycles, as well as occupying the base of the marine food web (Field et al., 1998). Whilst the impact of plastic particles upon biota has increasingly been studied, effects upon marine phytoplankton remain relatively little understood (Gao et al., 2021; Shen et al., 2020). These organisms are often the first to interact with contaminants of anthropogenic origin and are crucial to maintaining the health of the marine ecosystem. Plastic exposure has previously been associated with a reduction in fitness of marine phytoplankton (Gao et al., 2021), often characterised by reductions in algal growth and photosynthetic performance (Gao et al., 2021; Zhang et al., 2017; Prata et al., 2018). Adverse effects of plastics exposure have been recorded in green algae (Prata et al., 2018; Bergami et al., 2017; Venancio et al., 2019), diatoms (Zhang et al., 2017; Venancio et al., 2019; Baudrimont et al., 2020; Gonzalez-Fernandez et al., 2019; Bellingeri et al., 2020; Sendra et al., 2019) and cyanobacteria (de Oliveira et al., 2020; Machado et al., 2020; Fernandez-Juarez et al., 2020). However, findings vary (Davarpanah and Guilhermino, 2015; Long et al., 2017; Prata et al., 2019), and, in particular, evidence for the potential impact of nanoplastics upon marine phytoplankton is limited
(Wagner and Reemtsma, 2019; Venancio et al., 2019; Koelmans, 2019). While this is the case, preliminary evidence suggests that nano-sized plastic particles may be more detrimental to phytoplankton their larger counterparts (Zhang et al., 2017; Prata et al., 2019; Sjollema et al., 2016). The ocean represents a significant carbon sink and any adverse impact of plastic exposure could result in damages to oceanic carbon sequestration (Shen et al., 2020), a major concern given the threat of climate change. As such it is of high importance that additional research is carried out to reveal the possible impact of plastic particles spanning the micron-nanometre size range upon this ecologically important group of species.

Herein, we investigate the impact of $\sim 2 \mu \mathrm{m}$ polystyrene (PS) microspheres (MPs) and $\sim 50 \mathrm{~nm}$ polystyrene nanoparticles (NPs), representing the small plastic debris predicted to be abundant in the environment, upon marine phytoplankton. As mentioned above, the exact concentrations of such plastic debris in the environment remain uncertain (Piccardo et al., 2020), hence in our work supra-environmental concentrations $(\sim 100-100,000 \mathrm{X}$ those predicted in the environment) are utilised to provide insight into potential effects of exposure and to identify any threshold values for toxicity (Piccardo et al., 2020; Paul-Pont et al., 2018). First, we examined the natural marine community response towards plastics exposure, revealing a clear relationship between cell size and detrimental impacts upon phytoplankton growth. Here, greatest adverse effects were observed on larger eukaryotic species, whilst picocyanobacteria were little affected. This trend was subsequently confirmed by exposure of a range of laboratory cultured phytoplankton taxa varying in cell size and taxonomy in natural seawater. Adverse impacts were only recorded at concentrations exceeding those predicted in the environment. Using Emiliania huxleyi as a model, hetero-aggregation was revealed to be the key mechanism facilitating the decline of large phytoplankton in the presence of small plastic particles. Entrapment of cells within clusters of plastic aggregates and subsequent removal from the water column, alongside disruption to photosynthetic processes appeared the key features of plastic toxicity at supra-environmental concentrations.

\section{Methods}

\subsection{Materials}

Plastic particles used during experimental work were obtained from Spherotech ${ }^{\mathrm{TM}}$. Nanoplastics (NPs) and microplastics (MPs) were sized approximately $50 \mathrm{~nm}$ and $2 \mu \mathrm{m}$, respectively (see individual sections for specific details of particles used). Reagents used during experiments were obtained from Sigma Aldrich. Natural seawater (NSW) routinely used in experimental work was collected from Station L4, Plymouth $\left(50^{\circ} 15.0^{\prime} \mathrm{N} ; 4^{\circ} 13.0^{\prime} \mathrm{W}\right)$ and autoclaved prior to use.

\subsection{Natural community exposure}

\subsubsection{Natural phytoplankton incubations with $N P$ and $M P$}

Natural seawater (NSW) and its associated microbial community was collected from a pristine coastal location in Mallorca (39.493868-2.739820, November 2020) at a depth of $1 \mathrm{~m}$ and returned to the laboratory. After acclimation to experimental conditions, $20 \mathrm{~mL}$ of NSW was added to $25 \mathrm{~cm}^{2}$ rectangular cell culture flasks (Falcon) with vented caps and subsequently spiked with different concentrations of non-fluorescent spherical PS NPs (Spherotech PP-008-10, 50-100 nm) or MPs (Spherotech PP-20-10, $2.29 \mu \mathrm{m}$ ) to produce test concentrations of $0,0.00005 \%, 0.0005 \% .0 .005 \%$ and $0.05 \% \mathrm{w} / \mathrm{v}$ in triplicate. Here, non-fluorescent PS particles were used to allow for effective discrimination of distinct phytoplankton groups, which was disrupted in preliminary experiments with fluorescent particles. Flasks were maintained at $19{ }^{\circ} \mathrm{C}$ at a light intensity of $10 \mu \mathrm{mol}$ photons $\mathrm{m}^{-2} \mathrm{~s}^{-1}$ and placed on an orbital shaker (140 rpm). 
2.2.2. Monitoring the microbial community response to plastic exposure using flow cytometry

After 0, 24 and $72 \mathrm{~h}$, a $1 \mathrm{~mL}$ sub-sample was collected from each flask and fixed using $0.25 \%$ glutaraldehyde and $0.01 \%$ pluronic acid as previously recommended (Marie et al., 2014). Prior to their collection, samples were homogenized by pipetting. Fixed samples were analysed by flow cytometry using a Becton Dickinson FACS-Verse cytometer. FITC (488 nm excitation, 530/30 nm emission) and PE (488 nm excitation, 576/26 nm emission) together with FSC and SSC were used to separate the phytoplankton populations. Distinct phytoplankton groups were identified based upon their natural autofluorescence and gated using FACSDiva software. Cell densities were calculated in respect to spiked reference beads at a concentration of $10^{4}$ beads $\mathrm{mL}^{-1}(2.2 \mu \mathrm{m}$ high Intensity fluorescent Nile Red particles, Spherotech FH-2056-2). To identify statistical variations in cell density between untreated control and treated samples for each respective phytoplankton group, two-way T-tests were utilised at each timepoint $(\mathrm{p} \leq 0.05)$.

\subsection{Examining the response of model phytoplankton towards NP and MP exposure}

\subsubsection{Phytoplankton cultures}

Axenic phytoplankton cultures were routinely grown onsite at the University of Warwick: cyanobacteria Prochlorococcus sp. MED4 and Synechococcus sp. WH7803, green algae Micromonas sp. CMP2709 and Ostreococcus tauri OTH95, haptophyte Emiliania huxleyi CCMP1516, and diatoms Thalassiosira pseudonana CCMP1335 and Phaeodactylum tricornutum CCMP2561. Before plastic exposure, the phototrophs were routinely grown in axenic enriched media, ideal for each species as suggested by the literature (artificial seawater for Synechococcus; (Wilson et al., 1996) Pro99 for Prochlorococcus; (Moore et al., 2002) K-media for green algae and E. huxleyi; (Probert and Houdan, 2004; Keller et al., 1987) and F/2 media for diatoms) (Guillard, 1975).

\subsubsection{Phytoplankton culture growth in response to NP and MP exposure monitored by flow cytometry}

To examine the impact of plastic exposure upon the growth of marine phytoplankton, seven species were exposed to fluorescent PS NPs (Spherotech FP-00562-2, $50 \mathrm{~nm}$ ) or MPs (Spherotech FH-2056-2, 2.15 $\mu \mathrm{m}$ ) for a period of $72 \mathrm{~h}$. In contrast to work with natural phytoplankton described in Section 2.2.1, fluorescent particles could be used as clonal cultures form very defined populations that were clearly distinguished from the fluorescent NP and MPs. Axenic phytoplankton cultures of all seven species indicated above were routinely grown under optimal growth conditions as described in Section 2.3.1. To establish exposures under simulated natural cell concentrations, cultures were diluted 100X in oligotrophic NSW (Station L4, Plymouth) to a volume of $2 \mathrm{~mL}$ held within a 96-well plate and maintained at $23{ }^{\circ} \mathrm{C}$ under a constant light intensity of $10 \mu \mathrm{mol}$ photons $\mathrm{m}^{-2} \mathrm{~s}^{-1}$. NPs or MPs were added to cultures respectively to establish a test concentration of $0.001 \% \mathrm{w} / \mathrm{v}$. Phytoplankton were additionally exposed to copper sulphate to achieve a final $\mathrm{Cu}^{2+}$ concentration of $0,0.1,10$ and $10 \mu \mathrm{M}$ to act as a positive control and examine their response to a known pollutant. Cyanobacteria were additionally treated with lower $\mathrm{Cu}^{2+}$ concentrations $(0.001-0.05 \mu \mathrm{M})$ owing to their increased sensitivity. Treatments were set-up in triplicate and compared to an untreated control grown in the absence of plastics or $\mathrm{Cu}^{2+}$. Following 0,24 and $72 \mathrm{~h}$ growth, phytoplankton were monitored by flow cytometry using a Becton Dickinson Fortessa Flow Cytometer. Samples were homogenized by pipetting before collection and monitored directly, and phytoplankton gated using their natural autofluorescence using FACSDiva software. The abundance of phytoplankton was calculated relative to reference beads, as described previously. To identify statistical variations in cell density between untreated control and treated cultures for each species, two-way T-tests were utilised at each timepoint $(\mathrm{p} \leq 0.05)$.

\subsubsection{Phyto-PAM photosynthetic efficiency analysis}

The impact of plastic exposure upon the photosynthetic performance of marine phytoplankton was assessed by monitoring photosynthetic efficiency (Fv/Fm) following $72 \mathrm{~h}$ incubation. Axenic cultures of Prochlorococcus, $P$. tricornutum and E. huxleyi were prepared as described in Section 2.3.1 To establish exposures, cultures were diluted 100X in oligotrophic NSW (Station L4, Plymouth) to a volume of $100 \mathrm{~mL}$ held within 250-mL Erlenmeyer flasks. NPs (Spherotech FP-00562-2, $50 \mathrm{~nm}$ ) or MPs (Spherotech FH-2056-2, $2.15 \mu \mathrm{m}$ ) were added to flasks to establish a test concentration of $0.001 \% \mathrm{w} / \mathrm{v}$ in triplicate. Following exposure, Chlorophyll fluorescence was assessed at the end of the experiments using a PHYTO-PAM ${ }^{\circledR}$ Fluorometer Analyser (Walz, Germany) equipped with an ED-101US/ MP optical unit, without stirring to avoid any bias in fluorescence signal due to movement of cells between dark and illuminated zones in the cuvette (Echeveste et al., 2017). Fifteen mins before the measurements, samples were dark-acclimated to allow complete oxidation of PSII reaction centres, being F0 the minimum fluorescence yield measured at low intensity of modulated light $\left(<0.3 \mu \mathrm{mol}\right.$ photons $\left.\mathrm{m}^{-2} \mathrm{~s}^{-1}\right)$; and $\mathrm{Fm}$ the maximum fluorescence yield measured when all primary electron acceptors QA of PSII were reduced after a saturation pulse of $2.6 \mu \mathrm{mol}$ photons $\mathrm{m}^{-2} \mathrm{~s}^{-1}$ during $0.3 \mathrm{~s}$ (Genty et al., 1989). The maximal PSII quantum yield ( $\Phi \mathrm{M})$ of PSII was assessed, reflecting the state of the water photo oxidation process. Background fluorescence of plastics was determined using a blank sample with MPs or NPs added to culture media. An untreated control, where no plastics were added was also monitored. At the end of the experiment, two-way T-tests were carried out to identify statistical variations in photosynthetic efficiency between untreated control and treated cultures for each species $(\mathrm{p} \leq 0.05)$.

\subsubsection{Shotgun proteomic analysis of E. huxleyi exposed to NPs and MPS}

As a result of earlier works (section 2.3.2), the coccolithophore E. huxleyi was identified to be particularly sensitive towards plastics exposure. Shotgun proteomic analysis was utilised to identify molecular features of NPs (Spherotech FP-00562-2, $50 \mathrm{~nm}$ ) or MPs (Spherotech FH-2056-2, $2.15 \mu \mathrm{m}$ ) exposure upon the cellular proteome of $E$. huxleyi. Triplicate untreated and treated $E$. huxleyi cultures were obtained from photosynthetic efficiency experiments described above (section 2.3.3). Briefly, axenic E. huxleyi culture was diluted 100X in oligotrophic NSW (Station L4, Plymouth) to a volume of $100 \mathrm{~mL}$ as described above and exposed to NPs or MPs at a concentration of $0.001 \% \mathrm{w} / \mathrm{v}$, together with non-treated controls, all in triplicate. Following $72 \mathrm{~h}$ exposure, samples were immediately placed on ice to halt cellular activity. Subsequently, $100 \mathrm{~mL}$ samples were centrifuged $\left(4000 \mathrm{xg}\right.$ ) for $10 \mathrm{mins}$ at $4{ }^{\circ} \mathrm{C}$ to form a cell pellet. Cell pellets were immediately flash-frozen on dry ice and stored at $-20{ }^{\circ} \mathrm{C}$. After allowing cell pellets to thaw at room temperature, samples were resuspended in $1 \mathrm{X}$ LDS buffer (ThermoFisher) containing $1 \%$ beta-marcaptoethanol. To aid cell lysis, cell pellets were subjected to three cycles of 5 mins sonication (Branson 1210 Sonicator, $40 \mathrm{kHz}$ ), followed by incubation at $95^{\circ} \mathrm{C}$ and a short vortex. The resuspended cell pellets were then run on a precast NuPage 4-12\% Bis-Tris polyacrylamide gel at $200 \mathrm{~V}$ for a period of $5 \mathrm{~min}$ (Zadjelovic et al., 2020; Chhun et al., 2021). Gels were subsequently stained using SimplyBlue SafeStain (Invitrogen), and bands containing the cellular proteome were isolated and stored at $-20^{\circ} \mathrm{C}$ (Chhun et al., 2021). In-gel trypsin digestion and peptide recovery (Shevchenko et al., 2006) was carried out to prepare samples for nanoLC-ESI-MS/MS analysis. An UltiMate 3000 RSLCnano with Orbitrap fusion (Thermo Scientific) equipped with a $120 \mathrm{~min}$ LC separation on a $25 \mathrm{~cm}$ column was used to obtain RAW mass spectral files, as previously described (Christie-Oleza et al., 2015). Subsequently, MaxQuant version 1.5.5.1 (Cox and Mann, 2008) was used for peptide identification and protein label-free quantification (Cox et al., 2014), using default settings and "match between runs" for peptide identification. The Uniprot database for $E$. huxleyi used for peptide identification was downloaded on the 04/02/2017, to which coding domain sequences encoded by mitochondria and chloroplasts 
were included. Downstream analysis was carried out using Perseus version 1.5.5.3, after filtering of the data to remove potential contaminants (Chhun et al., 2021; Tyanova et al., 2016; Kaur et al., 2018). Two-way T-tests $(\mathrm{FDR} \leq 0.05)$ were utilised to assess significant alterations in protein expression between treated and control samples (volcano two-way T-test, $\mathrm{p} \leq 0.05$ ). Relative abundance of individual proteins was normalised to peptide length ${ }^{58}$ and utilised to calculate relative abundance of functional protein groups: basic cellular processes; carbon fixation; central metabolism; energy production and conversion; inorganic nutrient processing; other; oxidative stress; photosynthesis; membrane transport; and uncharacterized. Two-way T-tests ( $\mathrm{p} \leq 0.05$ ) were utilised to identify significant alterations in relative abundance of functional groups between treated and untreated cultures.

\subsubsection{Imaging of plastic-cell interactions using confocal microscopy}

The occurrence of plastic-cell hetero-aggregation was examined by carrying out fluorescent microscopy upon the coccolithophore $E$. huxleyi exposed to non-fluorescent spherical PS NPs (Spherotech PP-008-10, 50-100 nm) or MPs (Spherotech PP-20-10, $2.29 \mu \mathrm{m}$ ) following $72 \mathrm{~h}$ exposure. Here, non-fluorescent particles were used to avoid redundant signals of fluorescence and allow cells to be identified clearly. In this work cell-dense cultures $\left(10^{6}\right.$ cells $\left.\mathrm{mL}^{-1}\right)$ were utilised to facilitate imaging, exposed to NPs at a concentration of $0.05 \% \mathrm{w} / \mathrm{v} .2 \mathrm{~mL}$ cultures were added to a 96 -well plate and maintained under at $23{ }^{\circ} \mathrm{C}$ under a constant light intensity of $10 \mu \mathrm{mol}$ photons $\mathrm{m}^{-2} \mathrm{~s}^{-1}$. After $72 \mathrm{~h}, 20 \mu \mathrm{L}$ sub-samples were collected from the bottom of culture flasks and transferred to a glass microscope slide which was immediately imaged using a Leica TCS SPE confocal microscope (Leica Microsystems). Images were obtained using $E$. huxleyi chlorophyll autofluorescence (Ex/ Em 440/640-690 nm) and processed using the Leica application suite software (Leica Microsystems). In addition, sub-samples were collected and fixed for flow cytometric analysis, as described above (Section 2.2.2) to monitor changes in the planktonic free-living population.

\section{Results and discussion}

\subsection{Characterizing the natural community response to nano- and micro- plastic exposure}

Exposure of natural marine communities to NPs and MPs revealed significant impacts upon phytoplankton growth related to cell size, being larger phytoplankton more susceptible to plastic exposure than smaller phototrophs. This result is unexpected given the typical response
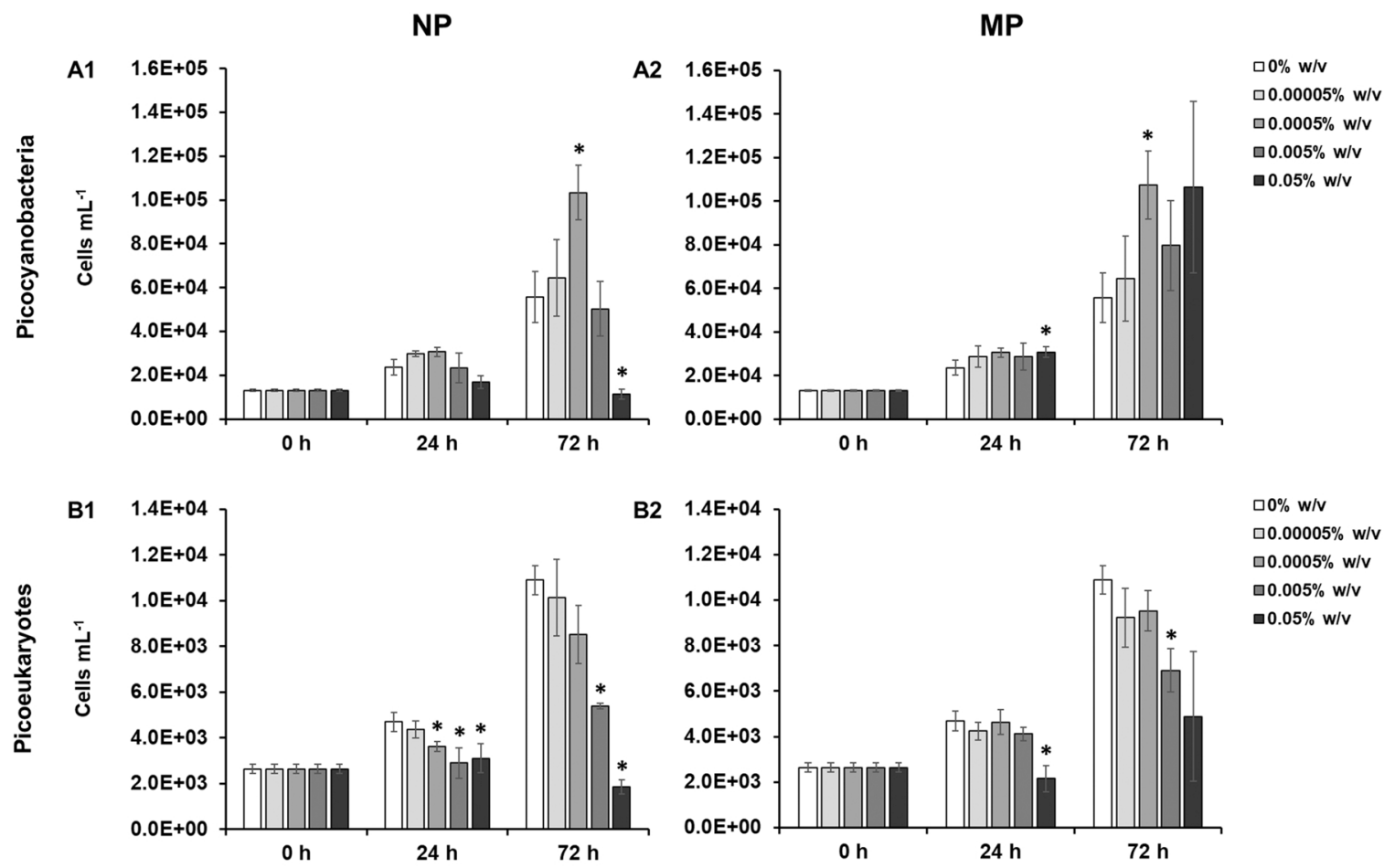

$\square 0 \% \mathrm{w} / \mathrm{v}$

$\square 0.00005 \% \mathrm{w} / \mathrm{v}$

$\square 0.0005 \% \mathrm{w} / \mathrm{v}$

$\square 0.005 \% \mathrm{w} / \mathrm{v}$

$-0.05 \% \mathrm{w} / \mathrm{v}$

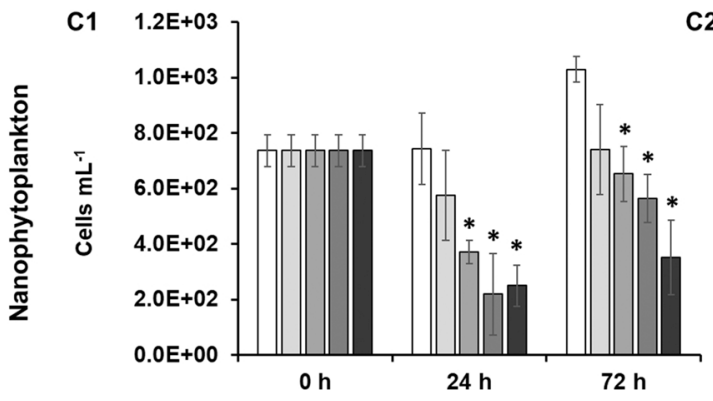

C2
$1.2 \mathrm{E}+03$
$1.0 \mathrm{E}+03$
$8.0 \mathrm{E}+02$
$6.0 \mathrm{E}+02$
$4.0 \mathrm{E}+02$
$2.0 \mathrm{E}+02$
$0.0 \mathrm{E}+00$

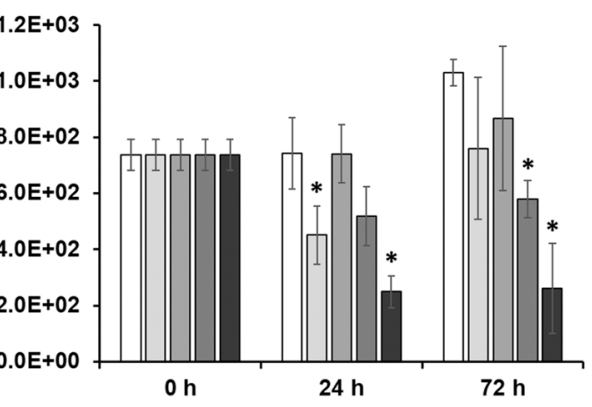

$\square 0 \% \mathrm{w} / \mathrm{v}$

$\square 0.00005 \% \mathrm{w} / \mathrm{v}$

$0.0005 \% \mathrm{w} / \mathrm{v}$

$\square .005 \% \mathrm{w} / \mathrm{v}$

$-0.05 \% \mathrm{w} / \mathrm{v}$

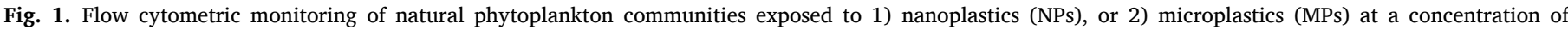

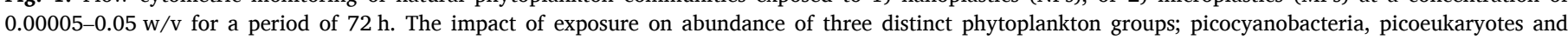

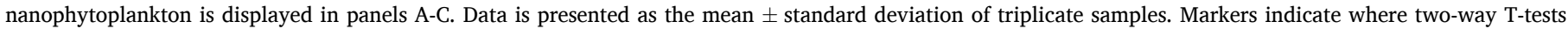
identified cell density to significantly vary between the untreated control and treated cultures at each timepoint ( $\mathrm{p} \leq 0.05$ ), respectively. 
of microorganisms to toxicants, where smaller organisms possessing relatively large surface-to-volume ratios experience greatest toxicity. However, the relationship between cell volume and extent of cell decline in response to NP or MP exposure was only apparent at supraenvironmental values, far exceeding those predicted in the environment. Hence, at environmentally-relevant plastic concentrations, negligible impact of plastic exposure upon natural marine photosynthetic communities was observed.

To date, the potential impacts of small ubiquitous plastic debris $(<1$ $\mathrm{mm}$ ) upon marine phytoplankton remained uncertain (Gao et al., 2021; Shen et al., 2020). To address this, we exposed a natural marine community to NPs $(\sim 50 \mathrm{~nm})$ and MPs $(2.29 \mu \mathrm{m})$, representing those small plastic particles believed abundant in the environment (Cozar et al., 2014; Poulain et al., 2019). NSW was incubated with NPs or MPs at a range of concentrations (i.e., $0.00005-0.05 \% \mathrm{w} / \mathrm{v}$, equating to $0.5-500$ $\mathrm{mg} \mathrm{L}^{-1}$ ) and phytoplankton growth was monitored by flow cytometry for a period of $72 \mathrm{~h}$ (Fig. 1). The abundance of distinct groups (i.e., picocyanobacteria and eukaryotes) was recorded based on their natural autofluorescence and cell morphology (Fig SI.1).

Based on their natural autofluorescence, three distinct phototrophic groups were identified and monitored by flow cytometry: picocyanobacteria identified mainly as Synechococcus sp. (Cyano), picoeukaryotes (Pico-Euk) and nanophytoplankton (Nano-Phyt). At $0 \mathrm{~h}$ Cyano were most abundant $\left(1.3 \times 10^{4}\right.$ cells $\left.\mathrm{mL}^{-1}\right)$, followed by Pico-Euk $\left(2.6 \times 10^{3}\right.$ cells $\left.\mathrm{mL}^{-1}\right)$ and Nano-Phyt $\left(7.4 \times 10^{2}\right.$ cells $\left.\mathrm{mL}^{-1}\right)$, respectively.

In NP exposures, no impact upon Cyano growth was recorded after $24 \mathrm{~h}$ (Fig. $1 \mathrm{~A} 1$ ). However, following $72 \mathrm{~h}$ in response to $0.05 \% \mathrm{w} / \mathrm{v} \mathrm{NPs}$, Cyano cell density was reduced approximately $79 \%$ compared to the untreated control (two-way T-test, $\mathrm{p} \leq 0.05$ ). Previous evidence of cyanobacterial decline in response to NP exposure has been recorded (de Oliveira et al., 2020; Machado et al., 2020). When incubated with $100 \mathrm{~nm}$ PS NPs $\left(0.0005 \% \mathrm{w} / \mathrm{v}, 5 \mathrm{mg} \mathrm{L}^{-1}\right)$ cyanobacteria were recorded to form aggregations with particles and settle out of the water column, representing a reduction in the planktonic population; however no adverse impact upon cell viability was recorded as cyanobacteria remained alive during this process (de Oliveira et al., 2020). It is likely that a similar process is responsible for the significant decline in the Cyano population at high NP concentrations recorded herein. In contrast, by the end of the experiment Cyano in the $0.0005 \% \mathrm{w} / \mathrm{v}$ treatment had grown to cell densities $86 \%$ higher than the untreated control (two-way T-test, $\mathrm{p} \leq 0.05$ ). As a result of MP exposure, no negative effect upon Cyano growth was recorded at any concentration (Fig. 1 A2). Rather, cell density remained on average higher than that of the untreated control throughout the experiment, significant after $24 \mathrm{~h}$ in the $0.05 \% \mathrm{w} / \mathrm{v}$ treatment (30\% increase relative to the control) and after $72 \mathrm{~h}$ in the $0.0005 \% \mathrm{w} / \mathrm{v}$ treatment (93\% increase relative to the control) (two-way T-test, $\mathrm{p} \leq 0.05$ ).

In response to plastic exposure, Pico-Euk cell density was on average lowered by NPs and MPs at every concentration at both $24 \mathrm{~h}$ and $72 \mathrm{~h}$ time points (Fig. 1B). This decline was more severe in NP treatments. Here, a significant decrease in Pico-Euk cell density was recorded after $24 \mathrm{~h}$ in NP treatments $\geq 0.0005 \% \mathrm{w} / \mathrm{v}$, resulting in a $23-60 \%$ decrease compared to the untreated control (two-way T-test, $\mathrm{p} \leq 0.05$ ). This decline continued throughout the experiment, causing a $51 \%$ and $83 \%$ decline in the $0.005 \%$ and $0.05 \% \mathrm{w} / \mathrm{v}$ NPs treatments respectively after $72 \mathrm{~h}$ (two-way T-test, $\mathrm{p} \leq 0.05$ ). In response to MPs, significant declines in Pico-Euk were recorded after $24 \mathrm{~h}$ in the $0.005 \% \mathrm{w} / \mathrm{v}$ treatment (37\%) and $0.05 \% \mathrm{w} / \mathrm{v}$ treatment after $72 \mathrm{~h}(54 \%)$ (two-way T-test, $\mathrm{p} \leq 0.05)$. In-line with the decline in smaller eukaryotic members, Nano-Phyt also experienced significant decreases in growth in response to both NPs and MPs (Fig. 1C). Similarly, concentrations $\geq 0.0005 \% \mathrm{w} /$ $\mathrm{v}$ NPs drove significant declines in large-sized Nano-Phyt populations after $24 \mathrm{~h}$, resulting in decreases of $50-70 \%$ compared to the untreated control (two-way T-test, $\mathrm{p} \leq 0.05$ ). At this timepoint, MPs at the $0.00005 \%$ and $0.05 \% \mathrm{w} / \mathrm{v}$ concentrations also drove relative cell declines of $39 \%$ and $67 \%$ respectively (two-way T-test, $\mathrm{p} \leq 0.05$ ). The significant declines observed in NP treatments continued to the end of the experiment, reaching a maximum decrease in cell density of $66 \%$ compared to the untreated control (two-way T-test, $\mathrm{p} \leq 0.05$ ). At this final timepoint, MP exposure $>0.005 \% \mathrm{w} / \mathrm{v}$ also drove significant declines of up to $75 \%$ (two-way T-test, $\mathrm{p} \leq 0.05$ ). Negative impacts of plastic exposure have previously been recorded in both algal and diatom species, discussed in greater detail in the following section (Venancio et al., 2019; Gonzalez-Fernandez et al., 2019; Bellingeri et al., 2020; Sendra et al., 2019; Casado et al., 2013; Besseling et al., 2014).

It appears from natural community exposure that smaller microorganisms (i.e., Cyano) are less affected by plastic exposure than larger eukaryotic members of the phototrophic community. Significant declines in the Cyano population are only recorded at extremely high concentrations where reductions in cell density likely arise from coaggregation with plastics and subsequent precipitation out of the water column (Long et al., 2017, 2015). Such effects have previously been recorded in cyanobacterial exposure to metal oxide nanomaterials (Dedman et al., 2021a, 2021b). Interestingly, evidence that presence of plastics can enhance the growth of picocyanobacteria was recorded in a number of treatments regardless of plastic size. Given that picocyanobacterial members dominated the phototrophic community, total cell density appears little affected by plastic exposure. However, this effect masks the negative effects experienced by larger eukaryotic members, which in terms of biomass can represent the equivalent of up to thousands of cyanobacteria. Indeed, larger eukaryotic phototrophs appear more susceptible to plastics, experiencing significantly reduced growth in response to both NP and MP treatments.

\subsection{Investigating the impact of nano- and micro- plastics upon growth of marine phytoplankton}

The enhanced susceptibility of larger phytoplankton to small plastic particles revealed during community exposure was subsequently confirmed by laboratory exposure of axenic phytoplankton cultures towards NPs and MPs. A total of seven phytoplankton species were selected for study, thus widening our knowledge on the possible effects of these contaminants, particularly in terms of NPs for which data is limited. Model species represented four taxonomic groups: cyanobacteria, green algae, diatoms and coccolithophores. In addition, to act as a positive control phytoplankton were exposed to dissolved $\mathrm{Cu}^{2+}$, a wellknown marine contaminant (Salomons and Forstner, 1984; Sadiq, 1992). Cultures were diluted in oligotrophic NSW to achieve natural-relevant cell concentrations to best represent natural conditions and exposed to plastics $(0.001 \% \mathrm{w} / \mathrm{v})$ or $\mathrm{Cu}^{2+}(0-10 \mu \mathrm{M})$, after which populations were monitored by flow cytometry for a period of $72 \mathrm{~h}$ (Fig SI.2).

Interestingly, in-line with results obtained during community exposure (Section 3.1), experimentation revealed both positive and negative impacts of plastic exposure upon phytoplankton growth (Table SI.1). Again, we observed that larger cells appeared to suffer greater adverse effects than their smaller counterparts when exposed to plastic particles as shown by the higher percentage change in cell density relative to the untreated control when plotted against cell volume following NP (Fig. 2A) or MP (Fig. 2B) exposure. $\mathrm{Cu}^{2+}$ was included as a control for the expected cell size- concentration effect of toxicity whereby smaller cells display highest sensitivity towards exposure, owing to their relatively high surface-to-volume ratios (Echeveste et al., 2010, 2011). As expected, cell with the lowest cell volumes exhibited highest sensitivity to $\mathrm{Cu}^{2+}$ (Fig. 2C). Here, $\mathrm{EC}_{50}$ values ranged from $0.05 \mu \mathrm{M}$ in the cyanobacteria Prochlorococcus and Synechococcus, to $6.65 \mu \mathrm{M}$ in the diatom T. pseudonana (Table SI.1).

Our findings suggest that the response of phytoplankton to plastic particles is largely taxa-specific, and appears related to cell size, but may also arise as a consequence of varied morphology and physiology. To assess any significant impact of plastic exposure upon phytoplankton growth, two-way T-tests were carried out to compare cell densities of 

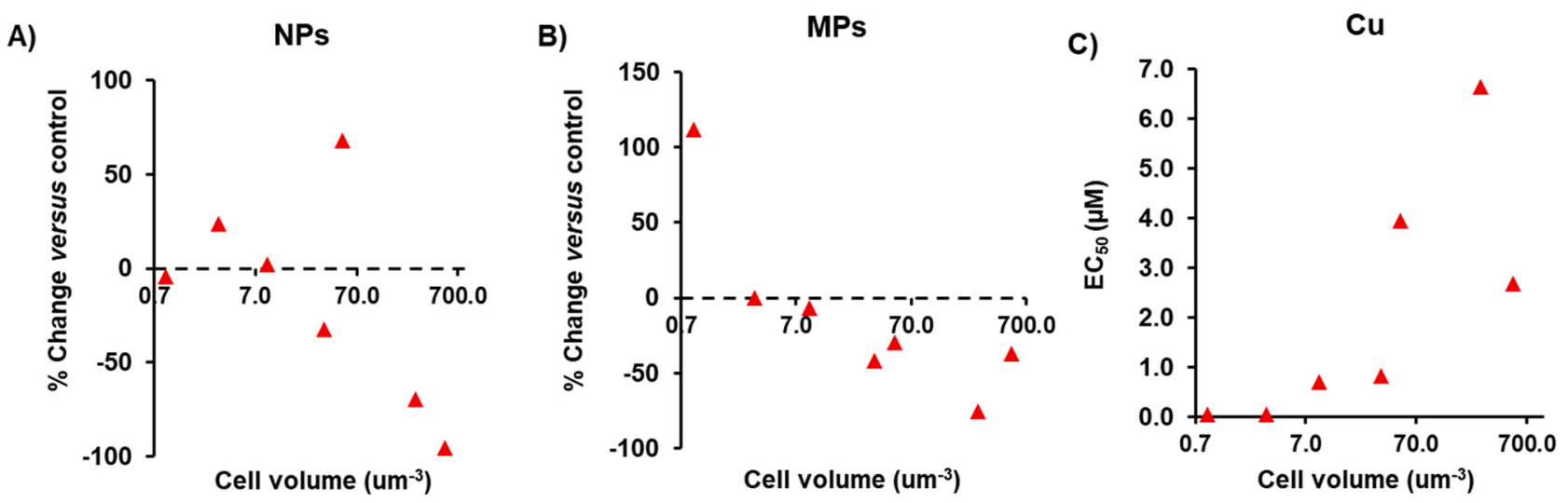

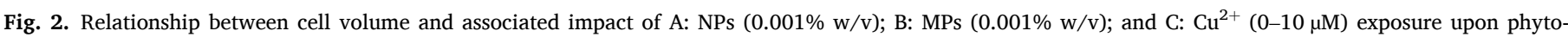

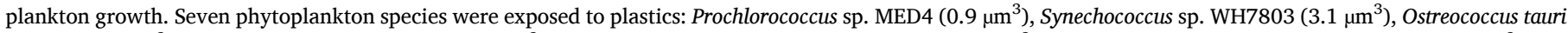

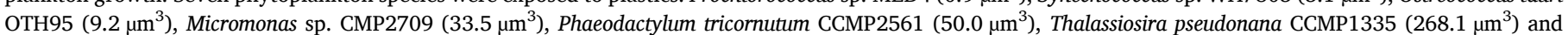
Emiliania huxleyi CCMP $1516\left(523.6 \mu \mathrm{m}^{3}\right)$.

untreated control cultures and those exposed to plastics $(0.001 \% \mathrm{w} / \mathrm{v})$ after $72 \mathrm{~h}$ (Fig SI.2). Notably, the coccolithophore E. huxleyi (Fig SI $0.2 \mathrm{G}$ ), representing the largest organism tested $\left(\sim 524 \mu \mathrm{m}^{3}\right)$, appeared particularly susceptible to plastic exposure. This species was significantly reduced by NPs, resulting in $95 \%$ loss of the population compared to the untreated control (two-way T-test, $\mathrm{p} \leq 0.05$; Fig. 2A). Although not statistically significant, MP exposure in this species also drove a decline in cell density of approximately $37 \%$ compared to the untreated control (two-way T-test, $\mathrm{p}=0.16$ ). Little work has been carried out examining the impact of plastic exposure towards coccolithophores, however, our results suggest this group may be particularly sensitive to plastic exposure at high concentrations. Coccolithophores play a key role in the marine carbon pump, both through their photosynthetic and calcification activities (Milliman, 1993; Westbroek et al., 1993). It is estimated in some zones, coccolithophores contribute approximately $20 \%$ of total carbon fixation (Poulton et al., 2007). These organisms produce calcite $\left(\mathrm{CaCO}_{3}\right)$ platelets named coccoliths which eventually sink towards the ocean floor where they remain for geological timescales (Jones et al., 2011). Dependent on the specific region, it is estimated that coccoliths can account for $20-80 \%$ of carbonate in marine sediments (Baumann et al., 2004). Hence, the enhanced susceptibility of coccolithophores towards plastic recorded herein is an ecological concern and requires greater investigation at environmentally-relevant plastic concentrations.

In previous work, diatoms have been identified as being sensitive to NP exposure (Zhang et al., 2017; Prata et al., 2018; Bergami et al., 2017; Venancio et al., 2019; Baudrimont et al., 2020). For example, following $96 \mathrm{~h}$ exposure to $50 \mathrm{~nm}$ PS- $\mathrm{NH}_{2}$ NPs $\left(0.0005 \% \mathrm{w} / \mathrm{v}, 5 \mathrm{mg} \mathrm{L}^{-1}\right)$ Chaetoceros neogracile was observed to experience a $62 \%$ decline in growth when incubated during the exponential growth phase (Gonzalez-Fernandez et al., 2019). Diatom species play a significant role in marine ecological functioning, contributing $\sim 20 \%$ towards global primary productivity (Malviya et al., 2016). In our work, the diatom T. pseudonana, representing the second largest species tested here $\left(\sim 268 \mu \mathrm{m}^{3}\right)$, also suffered declines in average cell density in response to both MPs and NPs, resulting in a respective decline of $75 \%$ and $70 \%$ in cell density (Fig. 2A-B and Fig SI $0.2 \mathrm{~F}$ ). However, due to variation between replicates this was not statistically significant (two-way T-test, $\mathrm{p}=0.16 ; 0.18)$. Unexpectedly, significantly enhanced growth following plastic exposure was also observed in the $P$. tricornutum $\left(\sim 50 \mu \mathrm{m}^{3}\right)$, appearing to be an outlier of the general trends observed (Fig. 2 and Fig SI.2E). Here, cell density of NP-treated cultures increased significantly by $68 \%$ relative to the control (two-way T-test, $\mathrm{p} \leq 0.05$ ). Evidence of improved phytoplankton growth in presence of plastics has previously been recorded in the freshwater microalga Raphidocelis subcapitata
(Canniff and Hoang, 2018). Hence, it appears that despite cell size playing an influential role in determining the likely impact of small plastic particles upon phytoplankton, there is evidence of species-specificity in response. As a result, differential sensitivity displayed by varying species may cause alterations to community structure and functioning, however this is only expected in high levels of plastic pollution given the high concentrations examined herein. Despite the enhanced growth of $P$. tricornutum recorded, evidence suggests that diatoms may be more susceptible to small plastic particles than other phytoplankton groups (Venancio et al., 2019). This is believed to be attributed to morphology (Venancio et al., 2019; Bellingeri et al., 2020) and the ability of diatoms to produce sticky exopolymeric substances (EPS), increasing the likelihood of adherence of NPs to cell structures (Venancio et al., 2019; Long et al., 2017). However, interestingly Grassi et al. (2020) found no adverse effect of negatively-charged PS-COOH NPs $\left(0-0.01 \% \mathrm{w} / \mathrm{v}, 0-100 \mathrm{mg} \mathrm{L}^{-1}\right)$ upon $P$. tricornutum after $72 \mathrm{~h}$ exposure in cultures supplemented with EPS, characterised by a reduction in intracellular ROS generation (Grassi et al., 2020). The presence of EPS was found to reduce aggregation of NPs, which were recorded to aggregate extensively upon entry into saline media, likely due to adsorption of EPS biomolecules onto the NP surface which is also hypothesised to enhance scavenging of harmful ROS (Grassi et al., 2020). Therefore, EPS may also mitigate plastic toxicity as well as facilitate physical cell-plastic interactions.

Green algae appear susceptible to both NP and MP exposure, however, again this is largely taxa specific as recorded in our work presented herein and in the literature (Venancio et al., 2019). The green algae, Ostreococcus suffered no negative effect of plastic exposure during experimentation (Fig SI $0.2 \mathrm{C}$ ), whereas average cell density of Micromonas was reduced by $32 \%$ and $42 \%$ in the presence of NPs and MPs respectively by the end of the experiment (Fig SI.2D). This result can be expected given that cell volume of Micromonas is approximately three-times that of Ostreococcus which represents the smallest known eukaryotic phototroph (Derelle et al., 2006). In previous research similar alterations in plastic impacts upon algal taxa are observed, with smallest cells also experiencing lowered sensitivity to exposure (Venancio et al., 2019).

NP exposure exerted no negative impact upon the smallest phytoplankton species tested: Prochlorococcus (Fig SI.2A) and Synechococcus 7803 (Fig SI.2B). In fact, cell density of Prochlorococcus was observed to display enhanced growth in the presence of MPs, resulting in a significant $112 \%$ increase in cell density (two-way T-test, $\mathrm{p} \leq 0.05$ ). 


\subsection{Mechanistic understanding of the adverse effect of NP and MP on} large-size phytoplankton

\subsubsection{Examining the impact of plastic exposure upon the photosynthetic} efficiency of marine phytoplankton

Primary productivity in the marine environment contributes approximately $50 \%$ of global oxygen production (Field et al., 1998), hence improving our understanding of the likely impact of plastic exposure upon the photosynthetic performance of marine phytoplankton is key. In previous research, disruption of normal photosynthetic function has been highlighted as a feature of exposure towards plastic particles (Gao et al., 2021; Gonzalez-Fernandez et al., 2019, 2020; Sendra et al., 2019). To investigate any alterations to photosynthetic function, a PHYTO-PAM fluorimeter was utilised to assess the photosynthetic efficiency ( $\mathrm{Fv} / \mathrm{Fm}$ ) of four phytoplankton species grown in presence of NPs or MPs $(0.001 \% \mathrm{w} / \mathrm{v})$ within oligotrophic NSW (Fig. 3). Exposure to both sizes of plastic resulted in a decline in average photosynthetic efficiency in all three species tested. In two species, $P$. tricornutum and E. huxleyi, only NP exposure caused a significant decline in photosynthetic efficiency compared to the untreated control (two-way T-test, $\mathrm{p} \leq 0.05$ ). Rather, in Prochlorococcus MP exposure significantly reduced photosynthetic performance (two-way T-test, $\mathrm{p} \leq 0.05$ ). For Prochlorococcus and $P$. tricornutum, average declines in Fv/Fm ranged $0.07-0.13$, representing declines of $15-35 \%$ in photosynthetic efficiency compared to the control. However, adverse effects on photosynthetic efficiency appeared most severe for $E$. huxleyi, shown above to be particularly susceptible to NP exposure (Section 3.2). Here, $\mathrm{Fv} / \mathrm{Fm}$ was recorded to decline from 0.39 in untreated cultures to 0.20 and 0.06 upon the addition of MPs and NPs, representing respective declines of $48 \%$ and $84 \%$ compared to the control.

A reduction in photosynthetic efficiency has previously been recorded in studies examining the impact of plastic exposure upon phytoplankton growth (Gao et al., 2021; Zhang et al., 2017; Bhattacharya et al., 2010; Mao et al., 2018). González-Fernández et al. (2020), reported that the photosynthetic machinery of the diatom C. neogracile was significantly altered after exposure to NPs (Gonzalez-Fernandez et al., 2020). In this work, a range photosynthetic pigments were significantly reduced (Gonzalez-Fernandez et al., 2020), believed to be a rapid photoprotective response to stress (Gonzalez-Fernandez et al., 2020; Kuczynska et al., 2015). Plastic exposure is often associated with a reduction in chlorophyll content (Zhang et al., 2017; Prata et al., 2018;
Gonzalez-Fernandez et al., 2019; Sendra et al., 2019; Besseling et al., 2014). For example, in response to $50 \mathrm{~nm}$ PS- $\mathrm{NH}_{2}$ both chlorophyll content and photosynthetic efficiency were reduced $33 \%$ and $13 \%$ respectively in the $C$. neogracile, resulting in a growth reduction of up to $62 \%$ (Gonzalez-Fernandez et al., 2019). Similar results have also been obtained during work examining freshwater species (J. Wu et al., 2019; Y. Wu et al., 2019). It is believed that such damages to photosynthetic pigments may arise from an increase in intracellular ROS which may damage pigment structure, or as a result of hetero-aggregation the entry of light and nutrients into the cell is compromised, thus reducing energy available for pigment synthesis or simply the need of sustaining such extensive photosynthetic machinery (Gao et al., 2021; Long et al., 2017; Geoffroy et al., 2003). Bhattacharya et al., 2010, utilised a $\mathrm{CO}_{2}$ depletion assay to demonstrate the ability of hetero-aggregations of plastic particles to hinder algal photosynthesis. Despite the evidence of damages to photosynthetic function of marine phytoplankton available, results vary, with evidence of enhanced photosynthetic performance also recorded (Long et al., 2017; Chae et al., 2019). In response to polyethylene MPs, D. salina displayed improved growth associated with an increase in chlorophyll content and improved photosynthetic efficiency, believed due to the release of trace levels of additives added to the plastic particles (Chae et al., 2019). Related to this, photosynthetic activity has also been recorded to improve when phytoplankton were exposed to expanded polystyrene leachate in four taxa (Chae et al., 2020). Further investigation is required to fully understand the likely impact of plastic exposure upon photosynthetic processes, particularly under environmental conditions.

\subsubsection{Shotgun proteomic analysis of E. huxleyi in response to nano- or micro- plastic exposure}

In response to plastic exposure, microorganisms may alter the regulation of specific cellular processes in order to adapt to- or mitigate stress. Plastic exposure has previously been associated with DNA damage $^{38}$ and altered gene function (Ripken et al., 2020; Lagarde et al., 2016) in marine phytoplankton. Owing to the apparent enhanced susceptibility of $E$. huxleyi towards plastics exposure observed during flow cytometric monitoring (Section 3.2) and examination of photosynthetic performance (section 3.3.1), this species was selected for further investigation of potential toxic mechanisms via shotgun proteomic analysis.

Following quality filtration of data, a total of 188 proteins in the

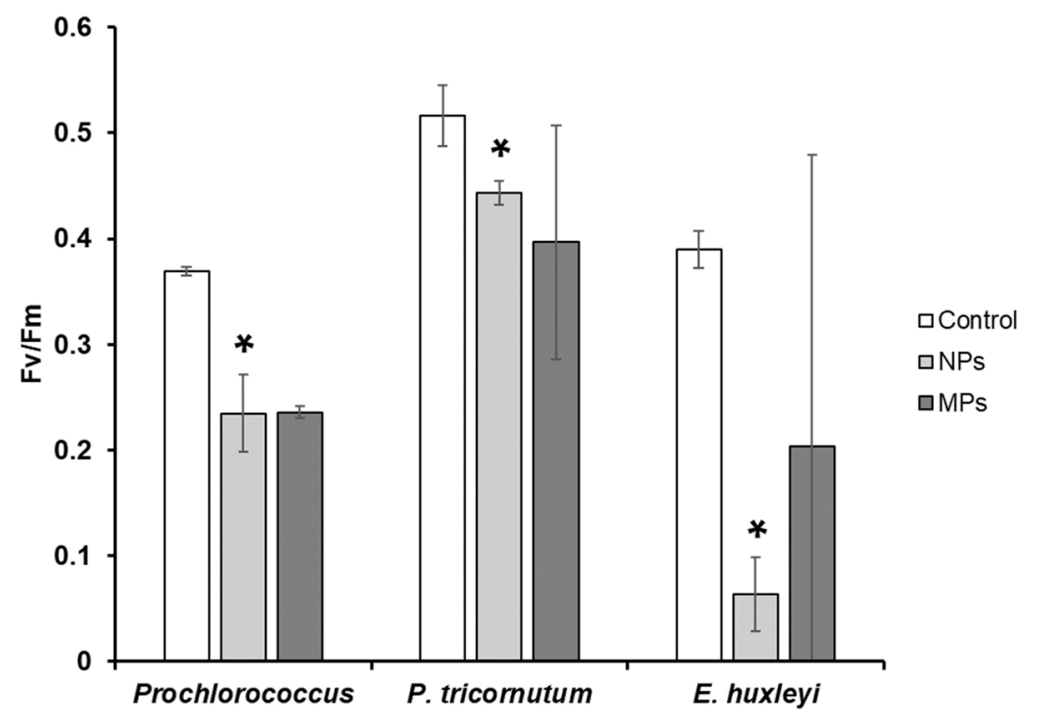

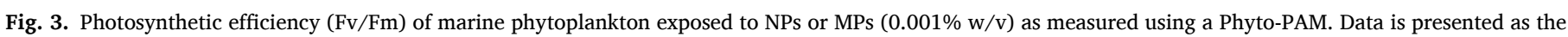

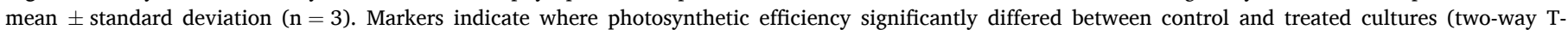
test, $\mathrm{p} \leq 0.05)$. 
cellular proteome of $E$. huxleyi were used for downstream analysis. Statistical analysis revealed nine individual proteins to be significantly altered in the presence of plastic particles (volcano two-way T-test, $\mathrm{p} \leq 0.05$ ). All significant proteins were identified in the NP treatment (Fig SI.3), each being significantly less abundant than in control cultures. Interestingly, no significant proteins were identified in the MP treatment, in accordance with earlier experiments displayed above which also reported no significant impact of MPs on growth or photosynthetic efficiency of $E$. huxleyi. Such findings are in accordance with previous research which observe enhanced impacts of plastic particles upon phytoplankton with decreasing particle size (Prata et al., 2019; Chae et al., 2019). Of the nine significant proteins identified, seven were annotated with a known function (Fig. 4): (A) ATP synthase subunit alpha, (B) ATP synthase gamma, (C) Light harvesting protein, (D) Photosystem I P700 chlorophyll a apoprotein A1, (E) Ribulose bisphosphate carboxylase large chain (RuBisCo), (F) Transketolase and (G) the putative EF-1 alpha/Tu like protein; all representing key proteins in the three relevant biological functions: energy production, photosynthesis and carbon fixation. The Photosystem I P700 chlorophyll $a$ apoprotein A1 involved in electron transport was decreased -2.48 Log2FC, whilst the light harvesting protein, usually part of a photosystem to enhance light capture was reduced by -3.47 2LogFC. Hence, the ability of $E$. huxleyi to effectively capture and utilise light energy may be compromised by the presence of NPs. This finding is in accordance with results obtained with the Phyto-PAM, displaying a significant decrease in photosynthetic efficiency in the presence of NPs. Reduced expression of chloroplastic genes was previously recorded in algal exposure to plastics in freshwater species (Lagarde et al., 2016). Notably, the key RuBisCo protein was downregulated approximately - 2.74 Log2FC, which alongside alterations in Transketolase abundance is likely to reduce carbon fixation, which in this ecologically important species may have environmental implications (Shen et al., 2020). In addition, through the decreased abundance of ATP synthase alpha and gamma, ATP production may be reduced.

Trends observed at the individual protein level are strengthened upon examining the relative abundance of functional proteins groups in each treatment (Fig SI.4). Once more, significant alterations are only observed in the NP treatment, where those proteins associated to photosynthesis and energy production are significantly decreased $\sim 14-10 \%$ and $\sim 9-4 \%$, respectively (two-way T-test, $\mathrm{p} \leq 0.05$ ). Also of note, proteins involved in central metabolism were on average more abundant in plastics treatments, $\sim 19 \%$ and $\sim 18 \%$ in the presence of NPs and MPs respectively, compared to $\sim 12 \%$ in the untreated control. Alterations to metabolic function have previously been recorded in cyanobacteria and diatom species in response to NPs (Gonzalez-Fernandez et al., 2019; Machado et al., 2020; Seoane et al., 2019).

Oxidative stress has previously been recorded as a feature of plastics exposure towards marine microbial organisms (Gao et al., 2021; Gonzalez-Fernandez et al., 2019; Bellingeri et al., 2020; Sendra et al., 2019; Bhattacharya et al., 2010; Sun et al., 2018). In our work, oxidative stress proteins were on average more abundant in the NP treatment compared to the control $(0.23 \%$ versus $0.08 \%)$, characterised primarily by an increase in superoxide dismutase. The induction of superoxide dismutase and malondialdehyde is described as a feature of plastic exposure in marine phytoplankton, a response that appears less severe in freshwater species (Gao et al., 2021). The increase in such antioxidant proteins is believed to arise due to the presence of ROS, or as a consequence of membrane damage caused by physical contact with plastic particles (Li et al., 2020). Oxidative stress arising from ROS generation appears a feature of NP exposure which may be enhanced at small particle sizes due to increased surface-area to volume and likelihood of internalisation. For example, after just $0.5 \mathrm{~h}$ exposure to $\mathrm{PS}-\mathrm{NH}_{2}$ $(50 \mathrm{~nm})$ and non-modified PS $(55 \mathrm{~nm}) \mathrm{NPs}\left(0.008 \% \mathrm{w} / \mathrm{v}, 80 \mathrm{mg} \mathrm{L}^{-1}\right)$ the intracellular ROS content of the marine proteobacterium $H$. alkaliphile was recorded to increase 4.4- and 7.7-fold respectively; whereas, no significant impact was observed in response to micron-sized PS (Sun et al., 2018). Significant increases in intracellular ROS have also been recorded in several diatom species (Gonzalez-Fernandez et al., 2019; Bellingeri et al., 2020; Sendra et al., 2019). P. tricornutum, displayed significant increases in intracellular ROS in response to PS NPs (50 and $100 \mathrm{~nm}$ ) during $72 \mathrm{~h}$ exposure where negative impacts upon growth were also recorded (Sendra et al., 2019). Similarly, C. neogracile experienced increased intracellular ROS generation up to $48 \%$ in response to PS- $\mathrm{NH}_{2}(50 \mathrm{~nm}$ ), reducing over time to $22 \%$ after $72 \mathrm{~h}$ (Gonzalez-Fernandez et al., 2019). Indeed it appears that intracellular ROS generation following NP exposure occurs most rapidly during early stages, after which ROS content is reduced over time (Gonzalez-Fernandez et al., 2019; Sendra et al., 2019; Sun et al., 2018). As well as increases in intracellular ROS content, NP exposure has been observed to enhance ROS generation outside of cells. Bellingeri et al.
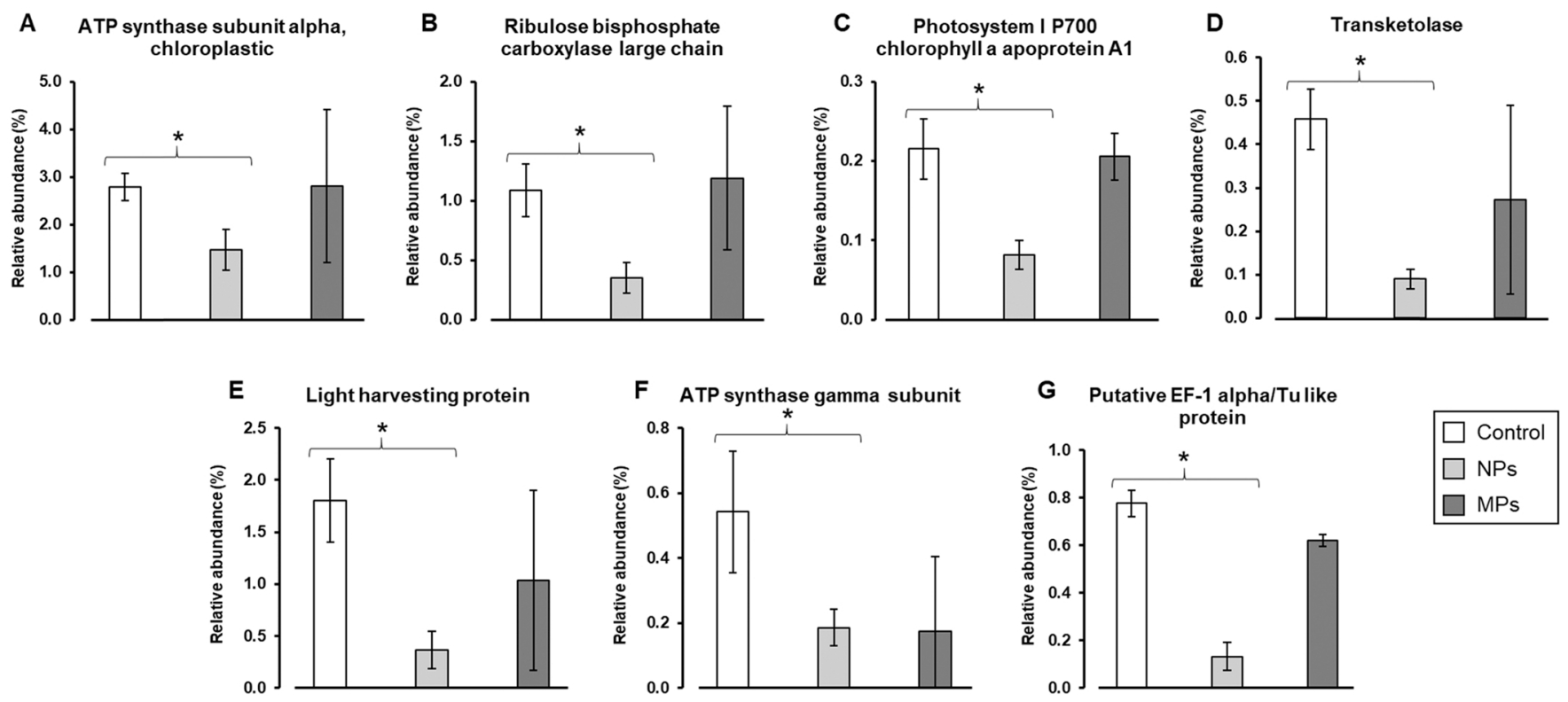

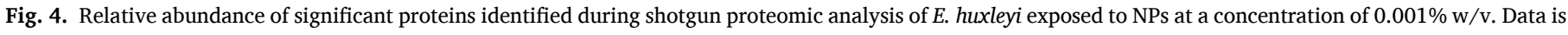
presented as the mean \pm standard deviation. 
(2020) recorded significant increase in extracellular ROS content in S. marinoi cultures exposed to PS-COOH NPs $(90 \mathrm{~nm})$ at a concentration of $0.005 \% \mathrm{w} / \mathrm{v}\left(50 \mathrm{mg} \mathrm{L}^{-1}\right)$. ROS production likely to cause lipid peroxidation, membrane instability, as well as damage to photosynthetic machinery and processes (Gonzalez-Fernandez et al., 2019), perhaps playing a role in phototoxicity previously described. Interestingly, the presence of supplementary EPS derived from diatom species has been observed to significantly reduce ROS production in the presence of PS-COOH NPs $(60 \mathrm{~nm})$ at similar concentrations $(0.001 \%$ and $0.005 \%$ $\mathrm{w} / \mathrm{v}, 10$ and $50 \mathrm{mg} \mathrm{L}^{-1}$ ) (Grassi et al., 2020). This suggests that EPS displays antioxidant activity (Grassi et al., 2020), or by its presence mitigates the production of ROS by plastics. In the natural environment where concentration of EPS and related material is likely higher, NP-mediated ROS generation may be mitigated.

\subsubsection{Hetero-aggregation of plastics and phytoplankton}

Confocal microscopy confirmed the occurrence of heteroaggregation between large phytoplankton such as E. huxleyi and plastic particles during laboratory exposure. Physical interaction between phytoplankton cells and plastic particles has been regularly reported (Bergami et al., 2017; Venancio et al., 2019; Gonzalez-Fernandez et al., 2019; Bellingeri et al., 2020; Sendra et al., 2019; de Oliveira et al., 2020; Ripken et al., 2020; Feng et al., 2020; Okshevsky et al., 2020). Typically, advanced imaging techniques (i.e., transmission/scanning electron microscopy, fluorescent microscopy) have typically been used to assess this phenomenon (Bergami et al., 2017; Bellingeri et al., 2020), with flow cytometric analysis also identified as a tool for this purpose (Sendra et al., 2019; Long et al., 2017). Hetero-aggregation is commonly associated with a decline in the phytoplankton population (Bergami et al., 2017; Okshevsky et al., 2020), as well as damaging cell morphology (Bellingeri et al., 2020) and photosynthetic performance (Bhattacharya et al., 2010). The direct impact of hetero-aggregation and subsequent co-precipitation and indirect effects upon photosynthetic performance are believed to be responsible for the significant declines recorded in large phytoplankton at supra-environmental plastic concentrations.

Herein, confocal microscopy was utilised to examine the occurrence and likely role of hetero-aggregation in driving significant declines in phytoplankton growth. Cultures of $E$. huxleyi, identified to be particularly susceptible to plastics exposure, were exposed to $\sim 50 \mathrm{~nm}$ NPs and $\sim 2 \mu \mathrm{m}$ MPs $(0.05 \% \mathrm{w} / \mathrm{v})$ for a period of $72 \mathrm{~h}$ before samples were prepared for imaging. Here, cell dense cultures were used to facilitate the imaging of cells which would be difficult in more dilute cultures. Samples were obtained from the bottom of culture flasks and the occurrence of hetero-aggregation following both NP (Fig. 5B) and MP exposure (Fig. 5C) was evident. Cells of E. huxleyi, identified using the natural autofluorescence of chlorophyll, could be seen entrapped within large aggregates of plastic particles which reached sizes exceeding $50 \mu \mathrm{m}$. To confirm that aggregated material did not consist of any other particulate matter, control samples where no plastics were added were also imaged (Fig. 5A), displaying no evidence of such material. Alongside imaging, sub-samples of exposed $E$. huxleyi culture were collected for cell enumeration by flow cytometry after $72 \mathrm{~h}$. Here, cell density was recorded to be reduced on average $95 \%$ and $43 \%$ relative to the untreated control, in response to NPs and MPs respectively (Fig SI.5). As such, it appears feasible to suggest that the cell declines recorded in E. huxleyi and other large phytoplankton above in response to plastic particles, are largely driven by hetero-aggregation and this may only occur at the relatively high plastic particle concentrations investigated. Following this, entrapped phytoplankton are removed from the water column via precipitation of aggregated material, as has previously been recorded (de Oliveira et al., 2020; Ripken et al., 2020; Okshevsky et al., 2020). This process, also observed during exposure with metal oxide nanomaterials (Dedman et al., 2021a, 2021b), is believed largely responsible for cases of reduced planktonic cell numbers or $\mathrm{OD}_{600}$
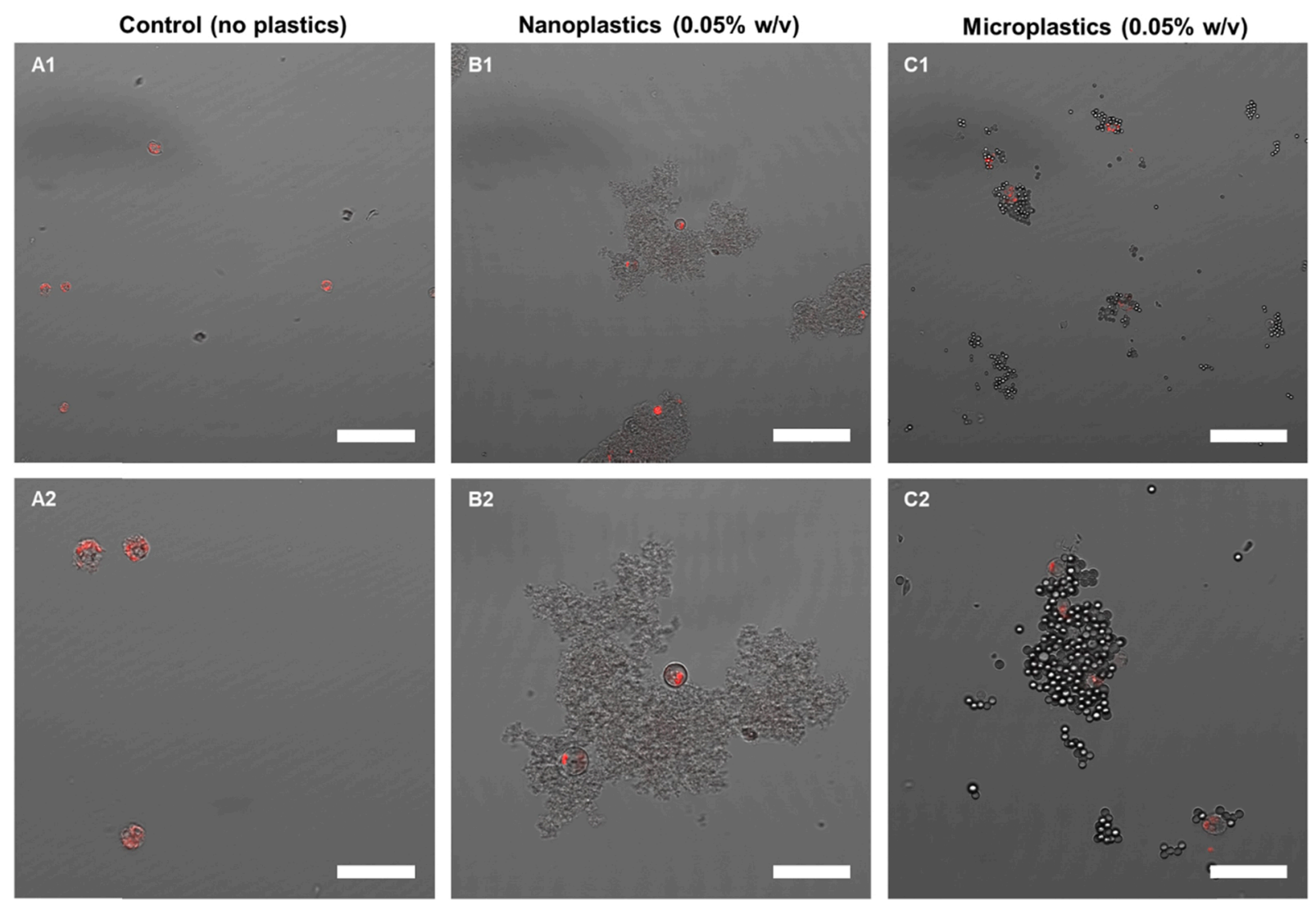

Fig. 5. Confocal microscopic imaging of Emiliania huxleyi cultures (red) exposed to; A) no plastics; B) nanoplastics; or C) microplastics, added at a concentration of $0.05 \% \mathrm{w} / \mathrm{v}$ for a period of $72 \mathrm{~h}$. Scale bar: $50 \mu \mathrm{m}$. 
recorded in toxicity testing (de Oliveira et al., 2020; Ripken et al., 2020; Okshevsky et al., 2020). Hetero-aggregation between plastic particles and phytoplankton may also act to disrupt photosynthetic processes through possible shading effects, also believed a possible feature of nanomaterial exposure during laboratory investigation (Hu et al., 2018). Large aggregates formed upon the cell surface may act to reduce light availability, compromising photosynthetic performance. Such an effect is in-line with results obtained from both photosynthetic efficiency assessment and shotgun proteomic analysis, earlier described (sections 3.3.1 and 3.3.2).

A range of taxa have been adversely impacted by plastics exposure in this manner including dinoflagellates (Ripken et al., 2020), cyanobacteria (de Oliveira et al., 2020) and heterotrophic bacteria (Okshevsky et al., 2020), in each case following exposure to PS NPs. Such processes may have important ecological consequences (Ripken et al., 2020; Schampera et al., 2021). For example, removal of symbiotic dinoflagellates has been recorded in experimentation with PS NPs $(42 \mathrm{~nm})$, which would likely affect their symbiotic relationship with coral species (Ripken et al., 2020). Hetero-aggregation between microbial cells and NPs may also facilitate the delivery of co-stressors which are effectively adsorbed and carried by the NP particles (Feng et al., 2020). Likewise, organisms occupying higher trophic levels may ingest such aggregates, facilitating the trophic transfer of plastics through the marine food web (Venancio et al., 2019). However, such effects are only likely in areas of extremely high plastic contamination.

According to the manufacturer's information, the PS particles utilised in our study possess sulfate groups on their surface and are negatively charged. Aggregation of negatively charged NPs upon entry into saline media is widely reported in the literature (Bergami et al., 2017; Grassi et al., 2020; Keller et al., 2010), due to maximised particle attachment following the compression of the electrostatic double layer surrounding individual particles in high ionic strength media (Zhou et al., 2013; Zhou and Keller, 2010). The increased extent of aggregation of negatively charged plastic particles such as those used in our study is likely to have played a key role in the entrapment of $E$. huxleyi within plastic aggregates evident by microscopy. Negatively charged PS-COOH NPs $(40 \mathrm{~nm}$ ) have previously been recorded to aggregate to sizes in the micron range and adhere to marine algal cells (Bergami et al., 2017). For positively charged particles such as $\mathrm{PS}-\mathrm{NH}_{2}$, aggregation with cells may also be facilitated by electrostatic attraction towards negatively charged cell surfaces (Bergami et al., 2017; Okshevsky et al., 2020).

The presence of natural organic material (NOM), largely comprised of dissolved organic matter (DOM) can have variable impacts on the aggregation of plastic particles, enhancing stability or aggregation dependent on specific environmental conditions and physicochemical properties of plastic (Cai et al., 2018). For example, addition of humic acid (HA) to artificial seawater has been recorded to promote aggregation of NPs in saline media due to a charge neutralisation effect, in turn reducing the stability of the NP suspension (Y. Wu et al., 2019; J. Wu et al., 2019; Tallec et al., 2019). However, HA has also been previously recorded to stabilise NP suspensions in artificial seawater, as well as promoting some disaggregation of particles, believed due to an increase in steric repulsion forces (Qu et al., 2010). The effect of organic matter on the stability of plastic particles is largely influenced by the surface charge of the plastic particle and ionic strength of media (Y. Wu et al., 2019; J. Wu et al., 2019; Tallec et al., 2019; Wang et al., 2021). For negatively charged NPs, as used in our study, DOM has previously been found to exert a stabilising effect (Y. Wu et al., 2019; J. Wu et al., 2019). However, as ionic strength of media is increased, this stabilising effect is overturned, and rather presence of organic matter increases aggregation processes likely due to cation ion bridging (Wang et al., 2021; Yu et al., 2019). It is believed that in natural seawater most PS NPs would rapidly aggregate and sink to deeper zones due to a combined effect of high ionic strength and presence of organic matter (Wang et al., 2021). The observation of sedimentation of the PS NPs and MPs during our study, which was conducted in natural seawater, supports this belief. This process likely plays a key role in the removal of cells from the water column as described above.

The production of EPS has previously been recorded as a defensive strategy utilised by microorganisms against nanomaterials (Chiu et al., 2017). Presence of these 'sticky' structures are thought to increase extent of hetero-aggregation between phytoplankton and NPs (de Oliveira et al., 2020; Okshevsky et al., 2020). Similarly, bacterial EPS, namely glycoprotein biopolymer, have also been found to aggregate with plastic particles within seawater (Summers et al., 2018). Addition of plastic particles has been found to increase EPS production, as well as alter its biochemical composition in phytoplankton (Shiu et al., 2020). For example, due to cellular stress arising from NP exposure, the protein to carbohydrate ratio of EPS produced by marine diatom species was increased, which in turn enhanced NP aggregation (Shiu et al., 2020). It is proposed that EPS or phytoplankton directly may play a key role in formation of large aggregates incorporating plastics, where EPS matrixes may act to concentrate NPs (Shiu et al., 2020; Chen et al., 2011), eventually facilitating the transportation of plastics and associated material to deeper zones via increased density (Shiu et al., 2020). In the case of E. huxleyi, coccolith formation and attachment during cell growth is associated with the production of polysaccharides (De Jong et al., 1976, 1979). The presence of these compounds may enhance plastic aggregation and the attachment of plastic particles to cells, playing a key role in their decline. However, results vary, and as mentioned above presence of EPS can also decrease the extent of aggregation of plastics (Grassi et al., 2020).

It is clear that naturally occurring organic material plays a key role in determining the environmental fate and likely interaction between plastic particles and biota in the marine environment. Evidence suggests that this effect can either enhance or reduce bioavailability of plastics and hence their potential toxicity as a result. A recurring finding is the belief that plastics, particularly NPs, will be incorporated into matrixes comprising of natural particulate material such as biogels and may eventually form a part of marine snow and be transported towards the sea floor. Through this action plastics may become increasingly bioavailable to species which occupy deeper zones of the water column, the effects of which require attention.

Specific cell structures have been associated with an increased risk from possible physical interaction with plastic particles, which may act to enhance a species' sensitivity to exposure (Venancio et al., 2019; Bellingeri et al., 2020). PS NPs were found to freely attach to the fultoportula process of diatoms, which act to form the phytoplankton's chain-structure (Bellingeri et al., 2020). As a consequence of attachment, NPs were believed to weaken these structures, associated with a reduction in diatom chain length as observed by microscopy (Bellingeri et al., 2020). Further investigation using scanning electron microscopy may provide insight into the physical interaction between plastic particles and the coccoliths of E. huxleyi.

It is clear that under laboratory conditions, physical interactions between plastic particles and microorganisms occur freely at the relatively high plastic concentrations that have largely been studied (i.e., $\mathrm{mg}$ $\mathrm{L}^{-1}$ ). It is important that we take such interactions into consideration when evaluating the outcome of exposure and identifying the primary cause of cell decline or reduction in fitness. The environmental implications of hetero-aggregation must also be considered, as well as the interaction of plastic particles with other naturally occurring particulate or dissolved organic matter under natural conditions (Summers et al., 2018). As described above aggregation between such material and plastic particles has previously been recorded to influence the stability of plastic suspensions. It is possible that presence of organic matter within NSW used in our work may also have enhanced aggregation processes and associated negative effects. Interactions between plastic particles and particulate or organic matter are likely to influence cell-plastic interaction and toxicity, as has been recorded in the presence of EPS (Grassi et al., 2020). Further research is required to identify the exact mechanisms that drive the physical interaction between 
phytoplankton and plastic particles observed during this study. Of course, due to dilution effects at the lower concentrations predicted in the environment (ng L ${ }^{-1}-\mu \mathrm{L} \mathrm{L}^{-1}$ ) (Lenz et al., 2016) this process of cell removal is less likely as the rate of encounter between phytoplankton and plastic particles is reduced.

\section{Conclusions}

In this study, we provide new information regarding the impact of nano- (NP) and micro- plastics (MP) upon marine phytoplankton which play key ecological roles. Exposure of both natural marine phytoplankton communities and laboratory cultures revealed that adverse outcomes of exposure to small plastic particles (NP, $\sim 50 \mathrm{~nm}$ and MP, $\sim 2 \mu \mathrm{m}$ ) are largely related to cell volume and taxonomy. Larger phytoplankton species appear particularly susceptible to plastic exposure, where effects appear enhanced with decreasing particle size. Smaller phytoplankton, on the other hand, appear little affected by exposure to NPs or MPs. Such results do not follow the traditional understanding of toxicity whereby smaller cells display greatest sensitivity due to relatively high surface-area-volume ratios. The coccolithophore E. huxleyi, representing the largest organism examined, was found to be most sensitive to plastic exposure, decreasing up to $95 \%$ in cell density following $72 \mathrm{~h}$ incubation with NPs $(50 \mathrm{~nm})$. These findings expand our current knowledge on plastic toxicity, particularly for nanoplastics for which limited data exists, and enables the prediction of the likely impacts of plastic exposure upon various phytoplankton.

Investigation into the drivers of cell declines exerted upon large phytoplankton by plastic exposure revealed hetero-aggregation between cells and large aggregates of plastic particles to be a key mechanism. Cells of $E$. huxleyi could clearly be seen entrapped within aggregates of both NPs and MPs by confocal microscopy. It is believed that the significant cell decline of $E$. huxleyi recorded within laboratory exposure, as well as for other large phytoplankton, largely results from entrapment and subsequent co-precipitation within aggregates of plastic particles, as has previously been demonstrated with metal oxide nanomaterials (Dedman et al., 2021a, 2021b). The enhanced susceptibility of large phytoplankton to plastic exposure relative to smaller cells is likely influenced by the fact that large cells have a wider cross section and, hence, straddle a wider set of streamlines within the water column, increasing their encounter rates (Shimeta and Koehl, 1997; Spielman, 1977). As a result, large phytoplankton such as E. huxleyi are likely to encounter higher numbers of plastic particles compared to smaller organisms like cyanobacteria. Consequently, rates of hetero-aggregation are increased relative to small cells, leading to large phytoplankton becoming more prone to removal from the water column by sedimentation. Other factors such as varied surface characteristics of cells, including surface roughness, may also contribute to differences in physical interactions between plastic particles and phytoplankton of varying size. The occurrence of hetero-aggregation and sedimentation of plastic particles may facilitate their accumulation in deeper zones and sediments, where benthic and sediment-dwelling organisms may experience increased exposure. Any impact of hetero-aggregation between plastics and phytoplankton upon plastic uptake by species which occupy higher trophic levels must be assessed, where it is possible that the presence of a biological signal may facilitate ingestion. However, it must be noted that herein such hetero-aggregation was only recorded at concentrations far exceeding those predicted in the environment. Exposure to NPs was also shown to cause damages to photosynthetic efficiency in E. huxleyi, as well as the diatom P. tricornutum and cyanobacteria Prochlorococcus. Significant impacts upon the cellular proteome of E. huxleyi following NP exposure were also recorded, specifically affecting processes of photosynthesis and carbon fixation. Entrapment within plastic aggregates likely reduces light availability due to shading effects and is likely responsible for the adverse effects upon the photosynthetic processes observed.

Global marine microplastic concentrations are predicted in the range of ng- $\mu$ g L ${ }^{-1}$ (Pabortsava and Lampitt, 2020; Lenz et al., 2016). The adverse effects recorded upon phytoplankton presented herein occur only at high concentrations $\left(\geq 0.0005 \% \mathrm{w} / \mathrm{v}, \geq 5 \mathrm{mg} \mathrm{L}^{-1}\right)$, orders of magnitude above the concentrations of plastic particles believed to be present in the marine environment. The negative effects associated with extensive aggregation of the PS NPs and MPs utilised in our experiments are likely exacerbated at the high concentrations used and closed-system nature of exposures and it is likely that negative effects reported in previous studies, largely carried out at concentrations in the $\mathrm{mg} \mathrm{L}^{-1}$ range, also result from this process. Hence, in accordance with risk assessments carried out by Everaert et al. (2018) the likely risk of small plastic particles towards marine phytoplankton within the natural environment is negligible. Whilst our findings reveal mechanistic insight into the potential effects of plastics upon key phytoplankton species, in the natural environment adverse effects appear limited to heavily polluted zones.

\section{CRediT authorship contribution statement}

Craig J. Dedman: Formal analysis, Writing - original draft. Joseph A. Christie-Oleza: Conceptualization, Funding acquisition, Investigation, Formal analysis, Writing - review \& editing. Víctor FernándezJuárez: Investigation, Formal analysis, Writing - review \& editing. Pedro Echeveste: Conceptualization, Funding acquisition, Investigation, Formal analysis, Writing - review \& editing.

\section{Declaration of Competing Interest}

The authors declare that they have no known competing financial interests or personal relationships that could have appeared to influence the work reported in this paper.

\section{Acknowledgements}

The research was funded through the Newton Fund Latin America Researcher Links Travel Grants (RLTG9-357288064) of the British Council. CJD was supported by the NERC CENTA DTP studentship NE/ L002493/1. JAC-O was funded by a NERC Independent Research Fellowship NE/K009044/1, Ramón y Cajal contract RYC-2017-22452 (funded by the Ministry of Science, Innovation and Universities, the National Agency of Research, and the European Social Fund) and project PID2019-109509RB-I00 / AEI / 10.13039/501100011033. PE was funded by Fondecyt Iniciación 11170837, REDI170403 and INACH-RT12-19. We also thank the technical assistance in imaging by Dr Ramis at the Cellomics Unit (IUNICS, SCT) of the University of the Balearic Islands, and Dr Marco Polin of the University of Warwick for their insight and useful discussion. In addition, we thank the BBSRC/EPSRC Synthetic Biology Research Centre WISB (grant ref.: BB/M017982/1) for access to equipment.

\section{Appendix A. Supporting information}

Supplementary data associated with this article can be found in the online version at doi:10.1016/j.jhazmat.2021.127488.

\section{References}

Cole, M., Lindeque, P., Halsband, C., Galloway, T.S., 2011. Microplastics as contaminants in the marine environment: a review. Mar. Pollut. Bull. 62 (12), 2588-2597.

Andrady, A.L., 2011. Microplastics in the marine environment. Mar. Pollut. Bull. 62 (8), 1596-1605.

Jambeck, J.R., Geyer, R., Wilcox, C., Siegler, T.R., Perryman, M., Andrady, A.,

Narayan, R., Law, K.L., 2015. Marine pollution. Plast. Waste Inputs Land into Ocean. Sci. 347 (6223), 768-771.

Eriksen, M., Lebreton, L.C., Carson, H.S., Thiel, M., Moore, C.J., Borerro, J.C., Galgani, F., Ryan, P.G., Reisser, J., 2014. plastic pollution in the world's oceans: more than 5 trillion plastic pieces weighing over 250,000 tons Afloat at Sea. PLoS One 9 (12), e111913. 
Hidalgo-Ruz, V., Gutow, L., Thompson, R.C., Thiel, M., 2012. Microplastics in the marine environment: a review of the methods used for identification and quantification. Environ. Sci. Technol. 46 (6), 3060-3075.

Cozar, A., Echevarria, F., Gonzalez-Gordillo, J.I., Irigoien, X., Ubeda, B., HernandezLeon, S., Palma, A.T., Navarro, S., Garcia-de-Lomas, J., Ruiz, A., Fernandez-dePuelles, M.L., Duarte, C.M., 2014. Plastic debris in the open ocean. Proc. Natl. Acad. Sci. USA 111 (28), 10239-10244.

Thompson, R.C., Olsen, Y., Mitchell, R.P., Davis, A., Rowland, S.J., John, A.W., McGonigle, D., Russell, A.E., 2004. Lost at sea: where is all the plastic? Science 304 (5672), 838.

Wright, S.L., Thompson, R.C., Galloway, T.S., 2013. The physical impacts of microplastics on marine organisms: a review. Environ. Pollut. 178, 483-492.

Cole, M., Lindeque, P., Fileman, E., Halsband, C., Goodhead, R., Moger, J., Galloway, T. S., 2013. Microplastic ingestion by zooplankton. Environ. Sci. Technol. 47 (12), 6646-6655.

Galloway, T.S., Lewis, C.N., 2016. Marine microplastics spell big problems for future generations. Proc. Natl. Acad. Sci. USA 113 (9), 2331-2333.

Lambert, S., Wagner, M., 2016. Characterisation of nanoplastics during the degradation of polystyrene. Chemosphere $145,265-268$.

Lambert, S., Sinclair, C.J., Bradley, E.L., Boxall, A.B., 2013. Effects of environmental conditions on latex degradation in aquatic systems. Sci. Total Environ. 447, 225-234.

Mattsson, K., Hansson, L.A., Cedervall, T., 2015. Nano-plastics in the aquatic environment. Environ. Sci. Process Impacts 17 (10), 1712-1721.

Koelmans, A.A., Besseling, E., Shim, W.J., 2015. Nanoplastics in the aquatic environment. Critical review. In: Bergmann, M., Gutow, L., Klages, M. (Eds.), Marine Anthropogenic Litter. Springer International Publishing, Cham, pp. 325-340.

Klaine, S.J., Alvarez, P.J., Batley, G.E., Fernandes, T.F., Handy, R.D., Lyon, D.Y., Mahendra, S., McLaughlin, M.J., Lead, J.R., 2008. Nanomaterials in the environment: behavior, fate, bioavailability, and effects. Environ. Toxicol. Chem. 27 (9), 1825-1851.

Hartmann, N.B., Huffer, T., Thompson, R.C., Hassellov, M., Verschoor, A., Daugaard, A. E., Rist, S., Karlsson, T., Brennholt, N., Cole, M., Herrling, M.P., Hess, M.C., Ivleva, N. P., Lusher, A.L., Wagner, M., 2019. Are we speaking the same language? Recommendations for a definition and categorization framework for plastic debris. Environ. Sci. Technol. 53 (3), 1039-1047.

Enfrin, M., Lee, J., Gibert, Y., Basheer, F., Kong, L., Dumee, L.F., 2020. Release of hazardous nanoplastic contaminants due to microplastics fragmentation under shear stress forces. J. Hazard Mater. 384, 121393.

Wagner, S., Reemtsma, T., 2019. Things we know and don't know about nanoplastic in the environment. Nat. Nanotechnol. 14 (4), 300-301.

Besseling, E., Redondo-Hasselerharm, P., Foekema, E.M., A, K.A., 2019. Quantifying ecological risks of aquatic micro- and nanoplastic. Crit. Rev. Environ. Sci. Technol 49 (1), 32-80.

Poulain, M., Mercier, M.J., Brach, L., Martignac, M., Routaboul, C., Perez, E., Desjean, M. C., 2019. Ter Halle, a., small microplastics as a main contributor to plastic mass balance in the north atlantic subtropical gyre. Environ. Sci. Technol. 53 (3), $1157-1164$.

Pabortsava, K., Lampitt, R.S., 2020. High concentrations of plastic hidden beneath the surface of the Atlantic Ocean. Nat. Commun. 11 (1), 4073

Nguyen, B., Claveau-Mallet, D., Hernandez, L.M., Xu, E.G., Farner, J.M., Tufenkji, N., 2019. Separation and analysis of microplastics and nanoplastics in complex environmental samples. Acc. Chem. Res. 52 (4), 858-866.

Everaert, G., Van Cauwenberghe, L., De Rijcke, M.;, Koelmans, A.A.; Mees, J.; Vandegehuchte, M.; Janssen, C.R., 2018. Risk assessment of microplastics in the ocean: modelling approach and first conclusions. Environ. Pollut. 242 (Pt B), 1930-1938.

Lenz, R., Enders, K., Nielsen, T.G., 2016. Microplastic exposure studies should be environmentally realistic. Proc. Natl. Acad. Sci. USA 113 (29), E4121-E4122.

Ter Halle, A., Jeanneau, L., Martignac, M., Jarde, E., Pedrono, B., Brach, L., Gigault, J., 2017. Nanoplastic in the North Atlantic subtropical gyre. Environ. Sci. Technol. 51 (23), 13689-13697.

Hassan, P.A., Rana, S., Verma, G., 2015. Making sense of Brownian motion: colloid characterization by dynamic light scattering. Langmuir 31 (1), 3-12.

Hotze, E.M., Phenrat, T., Lowry, G.V., 2010. Nanoparticle aggregation: challenges to understanding transport and reactivity in the environment. J. Environ. Qual. 39 (6), 1909-1924.

Field, C.B., Behrenfeld, M.J., Randerson, J.T., Falkowski, P., 1998. Primary production of the biosphere: integrating terrestrial and oceanic components. Science 281 (5374), 237-240.

Gao, G., Zhao, X., Jin, P., Gao, K., Beardall, J., 2021. Current understanding and challenges for aquatic primary producers in a world with rising micro- and nanoplastic levels. J. Hazard Mater. 406, 124685.

Shen, M., Ye, S., Zeng, G., Zhang, Y., Xing, L., Tang, W., Wen, X., Liu, S., 2020. Can microplastics pose a threat to ocean carbon sequestration? Mar. Pollut. Bull. 150, 110712.

Zhang, C., Chen, X., Wang, J., Tan, L., 2017. Toxic effects of microplastic on marine microalgae Skeletonema costatum: interactions between microplastic and algae. Environ. Pollut. 220 (Pt B), 1282-1288.

Prata, J.C., Lavorante, B., MDC, B.S.M.M., Guilhermino, L., 2018. Influence of microplastics on the toxicity of the pharmaceuticals procainamide and doxycycline on the marine microalgae Tetraselmis chuii. Aquat. Toxicol. 197, 143-152.

Bergami, E., Pugnalini, S., Vannuccini, M.L., Manfra, L., Faleri, C., Savorelli, F., Dawson, K.A., Corsi, I., 2017. Long-term toxicity of surface-charged polystyrene nanoplastics to marine planktonic species Dunaliella tertiolecta and Artemia franciscana. Aquat. Toxicol. 189, 159-169.
Venancio, C., Ferreira, I., Martins, M.A., Soares, A., Lopes, I., Oliveira, M., 2019. The effects of nanoplastics on marine plankton: a case study with polymethylmethacrylate. Ecotoxicol. Environ. Saf. 184, 109632.

Baudrimont, M., Arini, A., Guegan, C., Venel, Z., Gigault, J., Pedrono, B., Prunier, J., Maurice, L., Ter Halle, A., Feurtet-Mazel, A., 2020. Ecotoxicity of polyethylene nanoplastics from the North Atlantic oceanic gyre on freshwater and marine organisms (microalgae and filter-feeding bivalves). Environ. Sci. Pollut. Res. Int. 27 (4), 3746-3755.

Gonzalez-Fernandez, C., Toullec, J., Lambert, C., Le Goic, N., Seoane, M., Moriceau, B., Huvet, A., Berchel, M., Vincent, D., Courcot, L., Soudant, P., Paul-Pont, I., 2019. Do transparent exopolymeric particles (TEP) affect the toxicity of nanoplastics on Chaetoceros neogracile? Environ. Pollut. 250, 873-882.

Bellingeri, A., Casabianca, S., Capellacci, S., Faleri, C., Paccagnini, E., Lupetti, P., Koelmans, A.A., Penna, A., Corsi, I., 2020. Impact of polystyrene nanoparticles on marine diatom Skeletonema marinoi chain assemblages and consequences on their ecological role in marine ecosystems. Environ. Pollut. 262, 114268.

Sendra, M., Staffieri, E., Yeste, M.P., Moreno-Garrido, I., Gatica, J.M., Corsi, I., Blasco, J., 2019. Are the primary characteristics of polystyrene nanoplastics responsible for toxicity and ad/absorption in the marine diatom Phaeodactylum tricornutum? Environ. Pollut. 249, 610-619.

de Oliveira, T.T.S., Andreu, I., Machado, M.C., Vimbela, G., Tripathi, A., Bose, A., 2020. Interaction of cyanobacteria with nanometer and micron sized polystyrene particles in marine and fresh water. Langmuir 36 (14), 3963-3969.

Machado, M.C., Vimbela, G.V., Silva-Oliveira, T.T., Bose, A., Tripathi, A., 2020. The response of synechococcus sp. PCC 7002 to micro-/nano polyethylene particles investigation of a key anthropogenic stressor. PLoS One 15 (7), e0232745.

Fernandez-Juarez, V., Lopez-Alforja, X., Frank-Comas, A., Echeveste, P., BennasarFigueras, A., Ramis-Munar, G., Gomila, R.M., Agawin, N.S.R., 2020. "The Good, the bad and the double-sword" effects of microplastics and their organic additives in Marine Bacteria. Front Microbiol 11, 581118.

Davarpanah, E., Guilhermino, L., 2015. Single and combined effects of microplastics and copper on the population growth of the marine microalgae Tetraselmis chuii. Estuar., Coast. Shelf Sci. 167, 269-275.

Long, M., Paul-Pont, I., Hegaret, H., Moriceau, B., Lambert, C., Huvet, A., Soudant, P. 2017. Interactions between polystyrene microplastics and marine phytoplankton lead to species-specific hetero-aggregation. Environ. Pollut. 228, 454-463.

Prata, J.C., da Costa, J.P., Lopes, I., Duarte, A.C., Rocha-Santos, T., 2019. Effects of microplastics on microalgae populations: a critical review. Sci. Total Environ. 665, 400-405.

Koelmans, A.A., 2019. Proxies for nanoplastic. Nat. Nanotechnol. 14 (4), 307-308.

Sjollema, S.B., Redondo-Hasselerharm, P., Leslie, H.A., Kraak, M.H.S., Vethaak, A.D., 2016. Do plastic particles affect microalgal photosynthesis and growth? Aquat. Toxicol. 170, 259-261.

Piccardo, M., Renzi, M., Terlizzi, A., 2020. Nanoplastics in the oceans: theory, experimental evidence and real world. Mar. Pollut. Bull. 157, 111317.

Paul-Pont, I., Tallec, K., Gonzalez-Fernandez, C., Lambert, C., Vincent, D., Mazurais, D., Zambonino-Infante, J.-L., Brotons, G., Lagarde, F., Fabioux, C., Soudant, P., Huvet, A., 2018. Constraints and priorities for conducting experimental exposures of marine organisms to microplastics. Front. Mar. Sci. 5, 252.

Marie, D., Rigaut-Jalabert, F., Vaulot, D., 2014. An improved protocol for flow cytometry analysis of phytoplankton cultures and natural samples. Cytom. A 85 (11), 962-968.

Wilson, W.H., Carr, N.G., Mann, N.H., 1996. The effect of phosphate status on the kinetics of cyanophage infection in the oceanic cyanobacterium synechococcus sp. Wh7803. J. Phycol. 32 (4), 506-516.

Moore, L.R., Post, A.F., Rocap, G., Chisholm, S.W., 2002. Utilization of different nitrogen sources by the marine cyanobacteria Prochlorococcus and Synechococcus. Limnol. Oceanogr. 47 (4), 989-996.

Probert, I., Houdan, A., 2004. The Laboratory Culture of Coccolithophores. Springer, Berlin, Heidelberg.

Keller, M.D., Selvin, R.C., Claus, W., Guillard, R.R.L., 1987. Media for the culture of oceanic ultraphytoplankton. J. Phycol. 23 (4), 633-638.

Guillard, R.R.L., 1975. Culture of Phytoplankton for Feeding Marine Invertebrates. Springer, Boston, MA.

Echeveste, P., Silva, J.C., Lombardi, A.T., 2017. Cu and Cd affect distinctly the physiology of a cosmopolitan tropical freshwater phytoplankton. Ecotoxicol. Environ. Saf. 143, 228-235.

Genty, B., Briantais, J.M., Baker, N.R., 1989. The relationship between the quantum yield of photosynthetic electron transport and quenching of chlorophyll fluorescence. Biochim. Biophys. Acta - Gen. Subj. 990, 87-92.

Zadjelovic, V., Chhun, A., Quareshy, M., Silvano, E., Hernandez-Fernaud, J.R., AguiloFerretjans, M.M., Bosch, R., Dorador, C., Gibson, M.I., Christie-Oleza, J.A., 2020. Beyond oil degradation: enzymatic potential of Alcanivorax to degrade natural and synthetic polyesters. Environ. Microbiol. 22 (4), 1356-1369.

Chhun, A., Sousoni, D., Aguilo-Ferretjans, M.D.M., Song, L., Corre, C., Christie-Oleza, J. A., 2021. Phytoplankton trigger the production of cryptic metabolites in the marine actinobacterium Salinispora tropica. Micro Biotechnol. 14 (1), 291-306.

Shevchenko, A., Tomas, H., Havlis, J., Olsen, J.V., Mann, M., 2006. In-gel digestion for mass spectrometric characterization of proteins and proteomes. Nat. Protoc. 1 (6), 2856-2860.

Christie-Oleza, J.A., Scanlan, D.J., Armengaud, J., 2015. "You produce while I clean up", a strategy revealed by exoproteomics during Synechococcus-Roseobacter interactions. Proteomics 15 (20), 3454-3462.

Cox, J., Mann, M., 2008. MaxQuant enables high peptide identification rates, individualized p.p.b.-range mass accuracies and proteome-wide protein quantification. Nat. Biotechnol. 26 (12), 1367-1372. 
Cox, J., Hein, M.Y., Luber, C.A., Paron, I., Nagaraj, N., Mann, M., 2014. Accurate proteome-wide label-free quantification by delayed normalization and maximal peptide ratio extraction, termed MaxLFQ. Mol. Cell Proteom. 13 (9), 2513-2526.

Tyanova, S., Temu, T., Sinitcyn, P., Carlson, A., Hein, M.Y., Geiger, T., Mann, M., Cox, J., 2016. The Perseus computational platform for comprehensive analysis of (prote) omics data. Nat. Methods 13 (9), 731-740.

Kaur, A., Hernandez-Fernaud, J.R., Aguilo-Ferretjans, M.D.M., Wellington, E.M., Christie-Oleza, J.A., 2018. 100 days of marine synechococcus-ruegeria pomeroyi interaction: a detailed analysis of the exoproteome. Environ. Microbiol 20 (2), 785-799.

Casado, M.P., Macken, A., Byrne, H.J., 2013. Ecotoxicological assessment of silica and polystyrene nanoparticles assessed by a multitrophic test battery. Environ. Int. 51, 97-105.

Besseling, E., Wang, B., Lurling, M., Koelmans, A.A., 2014. Nanoplastic affects growth of S. obliquus and reproduction of D. magna. Environ. Sci. Technol. 48 (20), $12336-12343$.

Long, M., Moriceau, B., Gallinari, M., Lambert, C., Huvet, A., Raffray, J., Soudant, P., 2015. Interactions between microplastics and phytoplankton aggregates: impact on their respective fates. Mar. Chem. 175, 39-46.

Dedman, C.J., King, A.M., Christie-Oleza, J., Davies, G.-L., 2021a. Environmentally relevant concentrations of titanium dioxide nanoparticles pose negligible risk to marine microbes. Environ. Sci. Nano 8, 1236-1255.

Dedman, C.J., Rizk, M.M.I., Christie-Oleza, J.A., Davies, G.-L., 2021b. Investigating the impact of cerium oxide nanoparticles upon the ecologically significant marine cyanobacterium prochlorococcus. Front. Mar. Sci. 8, 571.

Salomons, W., Forstner, U., 1984. Metals in the Hydrocycle. Springer, Berlin.

Sadiq, M., 1992. Toxic Metal Chemistry in Marine Environments. Marcel Dekker Inc, New York.

Echeveste, P., Agusti, S., Dachs, J., 2010. Cell size dependent toxicity thresholds of polycyclic aromatic hydrocarbons to natural and cultured phytoplankton populations. Environ. Pollut. 158 (1), 299-307.

Echeveste, P., Agusti, S., Dachs, J., 2011. Cell size dependence of additive versus synergetic effects of UV radiation and PAHs on oceanic phytoplankton. Environ. Pollut. 159 (5), 1307-1316.

Milliman, J.D., 1993. Production and accumulation of calcium carbonate in the ocean: budget of a nonsteady state. Glob. Biogeochem. Cycles 7 (4), 927-957.

Westbroek, P., Brown, C.W., van Bleijswijk, J., Brownlee, C., Brummer, G.J., Conte, M., Egge, J., Fernandez, E., Jordan, R., Knappertsbusch, M., Stefels, J., Veldhuis, M., van der Wal, P., Young, J., 1993. A model system approach to biological climate forcing. The example of Emiliania huxleyi. Glob. Planet. Change 8 (1), 27-46.

Poulton, A.J., Adey, T.R., Balch, W.M., Holligan, P.M., 2007. Relating coccolithophore calcification rates to phytoplankton community dynamics: regional differences and implications for carbon export, 54 (5-7), 538-557.

Jones, B.M., Edwards, R.J., Skipp, P.J., O'Connor, C.D., Iglesias-Rodriguez, M.D., 2011. Shotgun proteomic analysis of Emiliania huxleyi, a marine phytoplankton species of major biogeochemical importance. Mar. Biotechnol. 13 (3), 496-504.

Baumann, K.-H., Boeckel, B., Frenz, M., 2004. Coccolith contribution to South Atlantic carbonate sedimentation. In: Thierstein, H.R.; Young, J.R. (Eds.), Coccolithophores: From Molecular Processes to Global Impact. Springer, Heidelberg, Germany, pp. 367-402.

Malviya, S., Scalco, E., Audic, S., Vincent, F., Veluchamy, A., Poulain, J., Wincker, P., Iudicone, D., de Vargas, C., Bittner, L., Zingone, A., Bowler, C., 2016. Insights into global diatom distribution and diversity in the world's ocean. Proc. Natl. Acad. Sci. USA 113 (11), E1516-E1525.

Canniff, P.M., Hoang, T.C., 2018. Microplastic ingestion by Daphnia magna and its enhancement on algal growth. Sci. Total Environ. 633, 500-507.

Grassi, G., Gabellieri, E., Cioni, P., Paccagnini, E., Faleri, C., Lupetti, P., Corsi, I., Morelli, E., 2020. Interplay between extracellular polymeric substances (EPS) from a marine diatom and model nanoplastic through eco-corona formation. Sci. Total Environ. 725, 138457.

Derelle, E., Ferraz, C., Rombauts, S., Rouze, P., Worden, A.Z., Robbens, S., Partensky, F., Degroeve, S., Echeynie, S., Cooke, R., Saeys, Y., Wuyts, J., Jabbari, K., Bowler, C., Panaud, O., Piegu, B., Ball, S.G., Ral, J.P., Bouget, F.Y., Piganeau, G., De Baets, B., Picard, A., Delseny, M., Demaille, J., Van de Peer, Y., Moreau, H., 2006. Genome analysis of the smallest free-living eukaryote Ostreococcus tauri unveils many unique features. Proc. Natl. Acad. Sci. USA 103 (31), 11647-11652.

Gonzalez-Fernandez, C., Le Grand, F., Bideau, A., Huvet, A., Paul-Pont, I., Soudant, P., 2020. Nanoplastics exposure modulate lipid and pigment compositions in diatoms. Environ. Pollut. 262, 114274.

Bhattacharya, P., Lin, S., Turner, J.P., Ke, P.C., 2010. Physical adsorption of charged plastic nanoparticles affects algal photosynthesis. J. Phys. Chem. 114 (39), $16556-16561$.

Mao, Y., Ai, H., Chen, Y., Zhang, Z., Zeng, P., Kang, L., Li, W., Gu, W., He, Q., Li, H., 2018. Phytoplankton response to polystyrene microplastics: perspective from an entire growth period. Chemosphere 208, 59-68.

Kuczynska, P., Jemiola-Rzeminska, M., Strzalka, K., 2015. Photosynthetic pigments in diatoms. Mar. Drugs 13 (9), 5847-5881.

Wu, Y., Guo, P., Zhang, X., Zhang, Y., Xie, S., Deng, J., 2019. Effect of microplastics exposure on the photosynthesis system of freshwater algae. J. Hazard Mater. 374, 219-227.

Geoffroy, L., Dewez, D., Vernet, G., Popovic, R., 2003. Oxyfluorfen toxic effect on S. obliquus evaluated by different photosynthetic and enzymatic biomarkers. Arch. Environ. Contam. Toxicol. 45 (4), 445-452.

Chae, Y., Kim, D., An, Y.J., 2019. Effects of micro-sized polyethylene spheres on the marine microalga Dunaliella salina: focusing on the algal cell to plastic particle siz ratio. Aquat. Toxicol. 216, 105296.
Chae, Y., Hong, S.H., An, Y.J., 2020. Photosynthesis enhancement in four marine microalgal species exposed to expanded polystyrene leachate. Ecotoxicol. Environ. Saf. 189, 109936.

Ripken, C., Khalturin, K., Shoguchi, E., 2020. Response of Coral Reef Dinoflagellates to Nanoplastics under Experimental Conditions Suggests Downregulation of Cellular Metabolism. Microorganisms 8, 1759.

Lagarde, F., Olivier, O., Zanella, M., Daniel, P., Hiard, S., Caruso, A., 2016. Microplastic interactions with freshwater microalgae: hetero-aggregation and changes in plastic density appear strongly dependent on polymer type. Environ. Pollut. 215, 331-339.

Seoane, M., Gonzalez-Fernandez, C., Soudant, P., Huvet, A., Esperanza, M., Cid, A., PaulPont, I., 2019. Polystyrene microbeads modulate the energy metabolism of the marine diatom Chaetoceros neogracile. Environ. Pollut. 251, 363-371.

Sun, X., Chen, B., Li, Q., Liu, N., Xia, B., Zhu, L., Qu, K., 2018. Toxicities of polystyrene nano- and microplastics toward marine bacterium Halomonas alkaliphila. Sci. Total Environ. 642, 1378-1385.

Li, S., Wang, P., Zhang, C., Zhou, X., Yin, Z., Hu, T., Hu, D., Liu, C., Zhu, L., 2020. Influence of polystyrene microplastics on the growth, photosynthetic efficiency and aggregation of freshwater microalgae Chlamydomonas reinhardtii. Sci. Total Environ. 714, 136767.

Feng, L.J., Shi, Y., Li, X.Y., Sun, X.D., Xiao, F., Sun, J.W., Wang, Y., Liu, X.Y., Wang, S.G., Yuan, X.Z., 2020. Behavior of tetracycline and polystyrene nanoparticles in estuaries and their joint toxicity on marine microalgae Skeletonema costatum. Environ. Pollut. 263 (Pt A), 114453.

Okshevsky, M., Gautier, E., Farner, J.M., Schreiber, L., Tufenkji, N., 2020. Biofilm formation by marine bacteria is impacted by concentration and surface functionalization of polystyrene nanoparticles in a species-specific manner. Environ. Microbiol Rep. 12 (2), 203-213.

Hu, J., Wang, J., Liu, S., Zhang, Z., Zhang, H., Cai, X., Pan, J., Liu, J., 2018. Effect of TiO2 nanoparticle aggregation on marine microalgae Isochrysis galbana. J. Environ. Sci. 66, 208-215.

Schampera, C., Wolinska, J., Bachelier, J.B., de Souza Machado, A.A., Rosal, R. Gonzalez-Pleiter, M., Agha, R., 2021. Exposure to nanoplastics affects the outcome of infectious disease in phytoplankton. Environ. Pollut. 277, 116781.

Keller, A.A., Wang, H., Zhou, D., Lenihan, H.S., Cherr, G., Cardinale, B.J., Miller, R., Ji, Z., 2010. Stability and aggregation of metal oxide nanoparticles in natural aqueous matrices. Environ. Sci. Technol. 44 (6), 1962-1967.

Zhou, D., Ji, Z., Jiang, X., Dunphy, D.R., Brinker, J., Keller, A.A., 2013. Influence of material properties on TiO2 nanoparticle agglomeration. PLoS One 8 (11), e81239.

Zhou, D., Keller, A.A., 2010. Role of morphology in the aggregation kinetics of ZnO nanoparticles. Water Res. 44 (9), 2948-2956.

Cai, L., Hu, L., Shi, H., Ye, J., Zhang, Y., Kim, H., 2018. Effects of inorganic ions and natural organic matter on the aggregation of nanoplastics. Chemosphere 197, $142-151$.

Wu, J., Jiang, R., Lin, W., Ouyang, G., 2019. Effect of salinity and humic acid on the aggregation and toxicity of polystyrene nanoplastics with different functional groups and charges. Environ. Pollut. 245, 836-843.

Tallec, K., Blard, O., Gonzalez-Fernandez, C., Brotons, G., Berchel, M., Soudant, P., Huvet, A., Paul-Pont, I., 2019. Surface functionalization determines behavior of nanoplastic solutions in model aquatic environments. Chemosphere 225, 639-646.

Qu, X., Hwang, Y.S., Alvarez, P.J.J., Bouchard, D., Li, Q., 2010. UV irradiation and humic acid mediate aggregation of aqueous fullerene (nC60) Nanoparticles. Environ. Sci. Technol. 44 (20), 7821-7826.

Wang, J., Zhao, X., Wu, A., Tang, Z., Niu, L., Wu, F., Wang, F., Zhao, T., Fu, Z., 2021. Aggregation and stability of sulfate-modified polystyrene nanoplastics in synthetic and natural waters. Environ. Pollut. 268 (Pt A), 114240.

Yu, S., Shen, M., Li, S., Fu, Y., Zhang, D., Liu, H., Liu, J., 2019. Aggregation kinetics of different surface-modified polystyrene nanoparticles in monovalent and divalent electrolytes. Environ. Pollut. 255 (Pt 2), 113302.

Chiu, M.H., Khan, Z.A., Garcia, S.G., Le, A.D., Kagiri, A., Ramos, J., Tsai, S.M., Drobenaire, H.W., Santschi, P.H., Quigg, A., Chin, W.C., 2017. Effect of engineered nanoparticles on exopolymeric substances release from marine phytoplankton. Nanoscale Res. Lett. 12 (1), 620.

Summers, S., Henry, T., Gutierrez, T., 2018. Agglomeration of nano- and microplastic particles in seawater by autochthonous and de novo-produced sources of exopolymeric substances. Mar. Pollut. Bull. 130, 258-267.

Shiu, R.F., Vazquez, C.I., Chiang, C.Y., Chiu, M.H., Chen, C.S., Ni, C.W., Gong, G.C., Quigg, A., Santschi, P.H., Chin, W.C., 2020. Nano- and microplastics trigger secretion of protein-rich extracellular polymeric substances from phytoplankton. Sci. Total Environ. 748, 141469.

Chen, C.S., Anaya, J.M., Zhang, S., Spurgin, J., Chuang, C.Y., Xu, C., Miao, A.J., Chen, E. Y., Schwehr, K.A., Jiang, Y., Quigg, A., Santschi, P.H., Chin, W.C., 2011. Effects of engineered nanoparticles on the assembly of exopolymeric substances from phytoplankton. PLoS One 6 (7), e21865.

De Jong, E., Bosch, L., Westbroek, P., 1976. Isolation and characterization of a Cat 2+Binding polysaccharide associated with coccoliths of Emiliania huxleyi (Lohmann) Kamptner. Eur. J. Biochem. 70 (2), 611-621.

De Jong, E., Van Rens, L., Westbroek, P., Bosch, L., 1979. Biocalcification by the Marine Alga Emiliania huxleyi (Lohmann) Kamptner. Eur. J. Biochem. 99 (3), 559-5567.

Shimeta, J., Koehl, M.A.R., 1997. Mechanisms of particle selection by tentaculate suspension feeders during encounter, retention, and handling. J. Exp. Mar. Biol. Ecol. 209 (1-2), 47-73.

Spielman, L.A., 1977. Particle capture from low-speed laminar flows. Annu. Rev. Fluid Mech. 9 (1), 297-319. 